\title{
Stress, Depression, and Neuroplasticity: A Convergence of Mechanisms
}

\author{
Christopher Pittenger ${ }^{1}$ and Ronald S Duman ${ }^{\star, 1}$ \\ ${ }^{1}$ Department of Psychiatry, Connecticut Mental Health Center, Yale University School of Medicine, New Haven, CT, USA
}

Increasing evidence demonstrates that neuroplasticity, a fundamental mechanism of neuronal adaptation, is disrupted in mood disorders and in animal models of stress. Here we provide an overview of the evidence that chronic stress, which can precipitate or exacerbate depression, disrupts neuroplasticity, while antidepressant treatment produces opposing effects and can enhance neuroplasticity. We discuss neuroplasticity at different levels: structural plasticity (such as plastic changes in spine and dendrite morphology as well as adult neurogenesis), functional synaptic plasticity, and the molecular and cellular mechanisms accompanying such changes. Together, these studies elucidate mechanisms that may contribute to the pathophysiology of depression. Greater appreciation of the convergence of mechanisms between stress, depression, and neuroplasticity is likely to lead to the identification of novel targets for more efficacious treatments.

Neuropsychopharmacology Reviews (2008) 33, 88-109; doi:10.1038/sj.npp.1301574; published online 12 September 2007

Keywords: synapse; neurogenesis; antidepressant; signal transduction; gene expression

\section{INTRODUCTION}

Over the past 50 years, different categories of effective antidepressant medications have been fortuitously discovered. All available antidepressants act on the brain's modulatory monoamine systems, an observation that formed the core of the monoamine hypothesis of the pathophysiology of depression (Heninger et al, 1996). More recently, molecular events downstream of antidepressants' direct actions on the monoamines have been elucidated, generating new theories about the pathophysiology of depression and the action of antidepressant medications (Duman et al, 1997), and new families of potential targets for novel antidepressant therapies (Manji et al, 2003).

A startling observation, as these downstream molecular events have been elucidated, is the striking degree of overlap between the molecular and cellular changes induced by antidepressant treatment and the molecular mechanisms of neuroplasticity, especially synaptic plasticity (see review by Citri and Malenka in this volume). Perhaps the most well-characterized instance of this fact is the transcription factor CREB, which has a well-established role in learningrelated synaptic plasticity in many organisms and brain regions (eg Bartsch et al, 1998; Pittenger et al, 2002;

${ }^{*}$ Correspondence: Dr RS Duman, Connecticut Mental Health Center, Yale University School of Medicine, 34 Park Street, Third Floor, New Haven, CT 6508, USA, Tel: +1 203974 7726, Fax: +1 2039747724 ,

E-mail: ronald.duman@yale.edu

Received 11 July 2007; revised 3 August 2007; accepted 4 August 2007 reviewed in Carlezon et al, 2005) and is involved in the hippocampus in antidepressant response (Thome et al, 2000; Chen et al, 2001a). Similar parallels have now been found in a multitude of other molecular events, synaptic alterations, and morphological changes, as we further review below. While the precise nature of the relationship between the pathophysiology of major depression and possible dysfunction of neuroplasticity remains poorly understood, it is likely that an intimate relationship exists.

In parallel, the interactions between chronic stress or a dysregulated stress response and the molecular, cellular, and behavioral changes that attend the development of a depression-like state have become increasingly clear. The relationship between psychosocial stressors and the development of depression in susceptible individuals has long been apparent (Kendler et al, 1999; Caspi et al, 2003). In experimental animals, stress can lead to atrophy of the hippocampus similar to that seen in depression (Sapolsky, 2000); chronic stress paradigms in animals recapitulate many of the core behavioral characteristics of depression and are responsive to antidepressant treatment (reviewed in Willner, 2005). The details remain to be elucidated, but any comprehensive picture of the pathophysiology of depression must include the role of stress in the etiology of the disorder.

Completing the circle, there is increasing appreciation of the effects of stress on the mechanisms of neuroplasticity (Shors et al, 1989; reviewed in McEwen, 1999). Clearly, then, there is an intimate relationship between the effects of stress, the mechanisms of neuroplasticity, and the pathophysiology of depression and mechanisms of antidepressant action. 
We explore this relationship in this review, outlining the major molecular and cellular pathways related to neuroplasticity that are altered by stress and appear to contribute to behaviors related to depression. We then discuss the mechanisms of antidepressant response, their overlap with mechanisms of neuroplasticity, and how they oppose the effects of chronic stress in various behavioral models. Together, these studies support a model of disruption of neuroplasticity by stress that contributes importantly to the pathophysiology of depression, and that is blocked or reversed by antidepressant treatment.

\section{IMPAIRMENTS OF LEARNING AND MEMORY IN MAJOR DEPRESSION}

Cognitive impairment is a core endophenotype of major depression (Hasler et al, 2004). One of the formal diagnostic criteria for the syndrome is a 'diminished ability to think or concentrate' (American Psychiatric Association, 2000), and patients often complain of difficulty with cognitive function during everyday tasks.

Cognitive difficulties in major depression fall into at least two domains, which are likely to correspond to different underlying disruptions of brain function. First, as indicated by the diagnostic criteria, is impairment of concentration and attention. Because the dorsolateral prefrontal cortex (DLPFC) is well established to play a critical role in these capacities, both in healthy humans and in experimental animals (Goldman-Rakic, 1996), this symptom is likely to relate to the well-documented abnormalities of DLPFC function in subjects with major depression (Baxter et al, 1989; Harvey et al, 2005) and to the finding of neuropathological change in this region in post-mortem tissue (Rajkowska et al, 1999, 2007).

Patients with major depression - both first episode and recurrent-also exhibit prominent deficits in explicit memory (Zakzanis et al, 1998), a cognitive capacity well established to depend on the function of the hippocampus and the medial temporal lobe (Squire et al, 2004). Hippocampal atrophy has been repeatedly documented in major depression: while the total number of neurons and glia has not been found to be altered, neurons are reduced in size and the volume of the neuropil is reduced (Stockmeier et al, 2004). Correspondingly, structural imaging has demonstrated decreased hippocampal size in patients with major depression, especially those who have suffered multiple episodes (MacQueen et al, 2003). It remains to be established whether reduced hippocampal size is the cumulative result of multiple major depressive episodes or whether it precedes the multiple episodes and represents a trait marker of vulnerability for recurrent disease; the two possibilities need not be mutually exclusive.

Disruption of hippocampal function, including the capacity for neuroplasticity, could contribute to several aspects of major depression. In addition to its clear role in declarative memory, the hippocampus is a key regulator of prefrontal cortical function; hippocampus and DLPFC function cooperatively to regulate explicit memory. Disruption of hippocampal function in major depression could therefore contribute to the observed deficits in concentration, described above. Hippocampal afferents are also critical regulators of both the nucleus accumbens and the ventral tegmental area (VTA). It has been hypothesized that an indirect excitatory projection from hippocampus to VTA is critical for coordinating the firing of VTA cells in response to novelty (Lisman and Grace, 2005); impairment of this hippocampal function could thus lead to reduced dopaminergic tone and contribute to anhedonia (WarnerSchmidt and Duman, 2006). Finally, the hippocampus provides an important source of negative modulation of the hypothalamus-pituitary-adrenal stress hormone axis through its projections to the hypothalamus; hippocampal dysfunction therefore may contribute to the dysregulation of the stress response that is seen in major depression.

\section{STRESS EFFECTS ON NEUROPLASTICITY: A PATHOPHYSIOLOGICAL CONTRIBUTOR TO MAJOR DEPRESSION?}

Chronic stress has many effects on the central nervous system, including effects on neuroplasticity in brain structures that are functionally abnormal in major depression. Given the clear clinical relationship between stress and major depression, these effects represent candidate pathophysiological links between stress, the mechanisms of neuroplasticity, and the development of major depressive disorder (MDD).

\section{Hippocampus: Effects of Prolonged Stress on Hippocampus-Dependent Memory, Plasticity, Cell Survival, and Neurogenesis}

Transient mild stress can enhance learning and memory (Luine et al, 1996). However, chronic or severe stress is decidedly disruptive of hippocampus-dependent memory in experimental animals (Conrad et al, 1996; de Quervain et al, 1998; Diamond et al, 1999; reviewed in Sapolsky, 2003). Extended or high-dose treatment with glucocorticoids has a similar effect (Bodnoff et al, 1995; de Quervain et al, 1998). Specific impairments of hippocampus-dependent explicit memory are also seen after treatment of human subjects with glucocorticoids (Newcomer et al, 1999; de Quervain et al, 2000) and after stress (reviewed in Shors, 2005).

Hippocampal synaptic plasticity, as modeled by longterm potentiation (LTP), is widely believed to represent an important component mechanism of hippocampus-dependent memory formation (Malenka and Bear, 2004; see Figure 1). It is therefore striking that a sufficiently severe stress can impair LTP in the rodent hippocampus (Foy et al, 1987; Shors et al, 1989; reviewed in Kim and Diamond, 2002). Conversely, similar stress paradigms in rodents enhance long-term depression (LTD) in the hippocampus (Xu et al, 1997); the two effects are likely to have overlapping mechanisms, as both are prevented by $N$ methy-D-aspartate (NMDA) blockade during the behavioral stress (Kim et al, 1996). The effect of serum glucocorticoids mirrors that of stress: low levels of glucocorticoids amplify LTP (perhaps through preferential activation of hippocampal mineralocorticoid receptors), while higher levels attenuate it (perhaps because they saturate the mineralocorticoid receptors and lead to robust activation of glucocorticoid receptors; reviewed in De Kloet, 2004). 

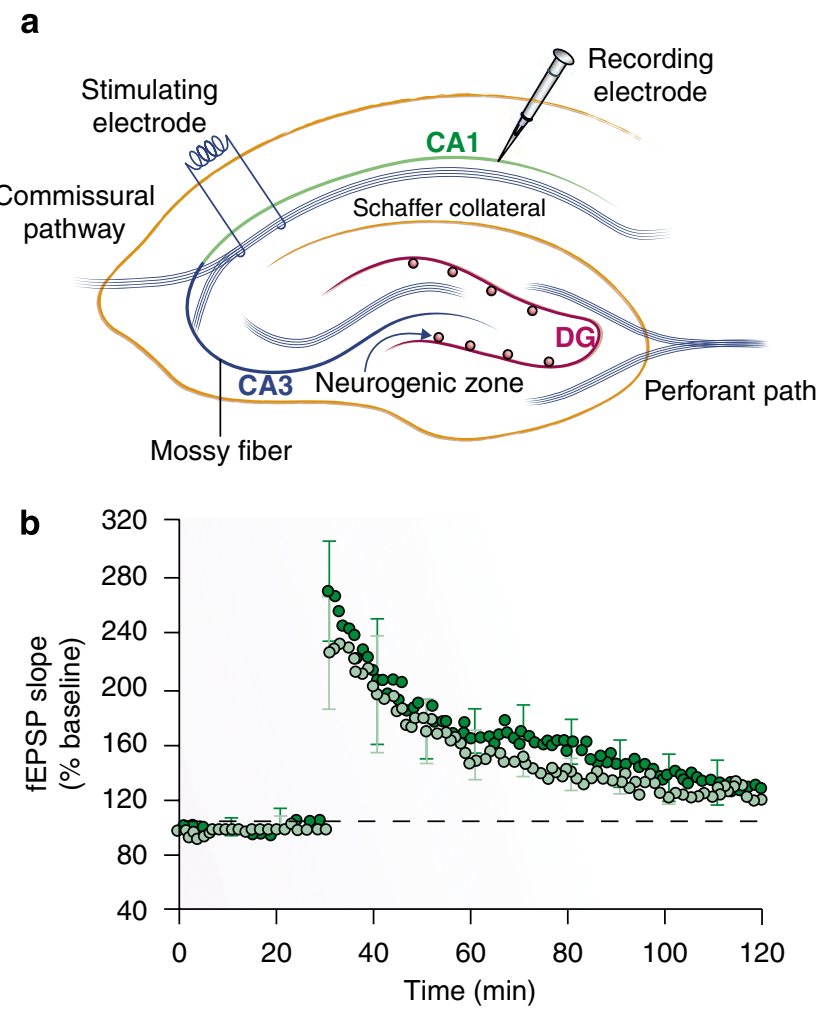

Figure I Hippocampal anatomy and sites of well-characterized forms of neuroplasticity. Neuroplasticity has been particularly intensively studied in the hippocampus. (a) Anatomy of the rodent hippocampus in coronal section is shown. Major synaptic projections include the perforant path from entorhinal cortex to dentate gyrus, the mossy fiber pathway from dentate gyrus to area CA3, and the Schaffer collateral pathway from area CA3 to area CAI. Other pathways exist but have been less intensively studied and are left out for clarity. Neurogenesis occurs in the subgranular cell zone of the dentate gyrus. (b) Synaptic plasticity has been characterized in all major synaptic pathways, but has been particularly intensively studied in the Schaffer collateral pathway; typical placement of stimulating and recording electrodes in an in vitro LTP experiment is shown.
Sustained levels of stress or glucocorticoids also damage the hippocampus at the level of morphological neuroplasticity (reviewed in Sapolsky, 2000) (Figure 2). Excess glucocorticoids (Woolley et al, 1990) or behavioral stress (Watanabe et al, 1992; Magarinos et al, 1996) lead to atrophy and retraction of the apical dendrites of hippocampal pyramidal cells; this effect leads to a reduction in the amount of neuropil without frank cell loss, reminiscent of what has been documented in the post-mortem hippocampus of patients with major depression (Stockmeier et al, 2004). Prolonged high-dose corticosterone - at higher levels than are typically achieved in vivo - can even result in death of hippocampal pyramidal cells (Sapolsky et al, 1985).

A final mechanism whereby prolonged stress can negatively impact hippocampal function and capacity for neuroplasticity has come to light more recently, with the broad acceptance of the presence of neurogenesis in the adult hippocampus (Figure 2). Many different forms of acute and chronic stress have been shown to reduce neurogenesis in the rodent hippocampus (reviewed in Duman, 2004; Dranovsky and Hen, 2006). Elevated levels of glucocorticoids likewise suppress hippocampal neurogenesis (Gould et al, 1992). As neurogenesis appears to be required for the behavioral response to antidepressants in rodents (Santarelli et al, 2003; see below) and impaired neurogenesis has been hypothesized to represent a core pathophysiological feature of major depression (Duman, 2004), this effect represents yet another way that the effects of stress on mechanisms of neuroplasticity may contribute to the development of depression.

\section{Prefrontal Cortex: Effects of Prolonged Stress on Morphology and Function}

While synaptic and morphological plasticity have been less intensively studied in the prefrontal cortex (PFC) than in the hippocampus, it is increasingly clear that stress has a
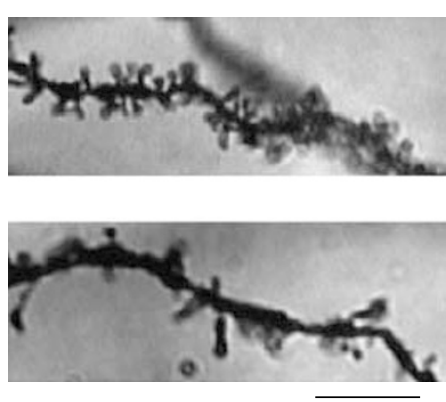

b

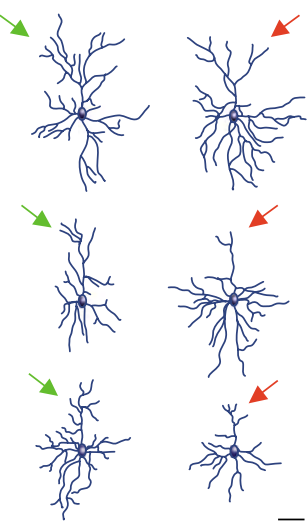

c
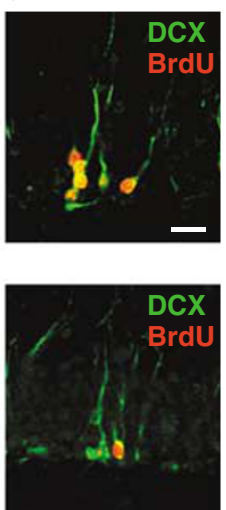

Figure 2 Stress alters neuroplasticity at multiple structural levels. (a) Chronic stress can reduce the number of dendritic spines. In this example, 8 weeks of postweaning social isolation produced a significant reduction in dendritic spines in mPFC in stress rat (lower panel) compared to controls (upper panel), as visualized by Golgi-Cox staining. From Silva-Gomez et al, 2003, with permission; scale bar $=5 \mu \mathrm{m}$. (b) Chronic stress can reduce the length and complexity of coritcal dendrites. In this example, repeated restraint stress ( $3 \mathrm{~h}$ a day for 3 weeks) produced shorter and less complex apical dendrites (indicated by arrows) in stressed rats (on the right) as compared to controls (on the left), as visualized in mPFC pyramidal neurons by computer-assisted resconstructions from Golgi-stained material. From Cook and Wellman, 2004, with permission; scale bar $=50 \mu \mathrm{m}$. (c) Chronic stress can impair neurogenesis. In this example, 3 weeks of daily unpredictable stressors reduced the generation of new neurons in the rat dentate gyrus (lower panel) compared to unstressed controls (upper panel). Neurogenesis is visualized by labeling with bromo-deoxyuridine (BrdU), which labels recently divided cells, and doublecortin (DCX), a marker of immature neurons. Ja-Wook Kim and RSD; scale bar $=20 \mu \mathrm{m}$. 
similar effects on the mechanisms of neuroplasticity there. Chronic restraint stress induces significant regression of the apical dendrites of pyramidal cells in medial prefrontal cortex (mPFC) in rats, an effect similar to that described in area CA3 of the hippocampus (Cook and Wellman, 2004; Radley et al, 2004). The effect may be specific to mPFC, as orbital PFC is spared (Liston et al, 2006). Attentional setshifting, a behavioral task that depends on intact mPFC function, is impaired in chronically stressed animals (Liston et al, 2006). A similar effect is seen following chronic administration of corticosterone (Wellman, 2001). Again, this morphological change appears to recapitulate some of the changes seen in post-mortem tissue from patients with MDD (Rajkowska et al, 1999).

One of the most consistent neuropathological findings in MDD is a reduction in the number of glia (Ongur et al, 1998; Rajkowska et al, 1999; Cotter et al, 2001, 2002; Uranova et al, 2004). In animals, chronic unpredictable stress results in a reduction in the proliferation of glia and endothelial cells in the mPFC (Banasr et al, 2007); exposure to glucocorticoids causes a similar effect (Alonso, 2000). Glia provide metabolic support for neurons; a reduction in the numbers of these cells could impact the function as well as morphology of mPFC pyramidal cells. Glia also play an important role in both the synthesis and inactivation of glutamate, which is central to many forms of neuroplasticity (a point to which we return below). Altered number or function of glia could thereby impact neuroplasticity. Stress-induced reductions in glial proliferation could contribute to the decrease in glial number observed in MDD and to a decrease in neural plasticity.

It is tempting to speculate that such stress-induced atrophy of prefrontal dendrites and a reduction in glial number contribute to the 'hypofrontality' observed in patients with major depression (see above). Some data support an effect of chronic stress on prefrontal physiology and information processing. For example, acute stress can perturb synaptic plasticity at the projection from amygdala to PFC (Maroun and Richter-Levin, 2003). At the reverse projection, from PFC to amygdala, stress shifts the balance from one that favors LTD to one that favors LTP (Maroun, 2006).

While the precise contribution of such perturbations to the network changes in brain function that characterize the depressed state is difficult to infer, these findings support the notion that sufficient levels of stress alter the mechanisms of neuroplasticity in a group of interconnected structures, which are functionally abnormal in major depression. Furthermore, even though only a few studies have examined synaptic plasticity in these structures after stress, the directions of the documented changes are concordant with the abnormalities seen in major depression. PFC is hypoactive in major depression; and potentiation of a major excitatory pathway leading to it is attenuated by stress. Conversely, the amygdala is hypertophic and hyperactive in major depression, and potentiation of a major input to it - from the ventro mPFC - is enhanced.

\section{Amygdala: Stress-Induced Hypertrophy}

Whereas the hippocampus and PFC are both reduced in size and activity in major depression, the amygdala's size and activity are increased (reviewed in Drevets, 2003). Several structural imaging studies have reported increased amygdala volume in patients with major depression (Bremner et al, 2000; Frodl et al, 2002; Lange and Irle, 2004). The amygdala has also been found to be hyperactive in major depression (Drevets et al, 1992); its activity correlates with the intensity of negative affect (Drevets et al, 1992; Abercrombie et al, 1998).

Chronic stress can enhance amygdala-dependent learning, in contrast to its effects on hippocampus-dependent declarative learning. In rats, chronic stress enhances amygdala-dependent fear learning (Conrad et al, 1999). It also enhances behavioral measures of anxiety in experimental animals (Conrad et al, 1999; Vyas et al, 2004).

Correspondingly, stress enhances synaptic plasticity and the function of amygdala neurons, an effect quite distinct from the atrophy it induces in the hippocampus and PFC. This could both result from and contribute to overactivation of neuronal circuits that control fear, anxiety, and emotion. In rats, stress that leads to atrophic changes in hippocampal pyramidal cells produces enhanced dendritic length and branching in amygdala principal cells and in the bed nucleus of the stria terminalis, an important amygdala projection target (Vyas et al, 2002, 2003). Prolonged stress increases dendritic spines and synaptic connectivity in the amygdala (Vyas et al, 2006). Interestingly, these changes do not reverse even several weeks after the cessation of the chronic stressor (Vyas et al, 2004). Indeed, the effects of stress on the amygdala maybe very long-lasting indeed: in rats, prenatal stress can lead to increased amygdala size in adulthood (Salm et al, 2004). If replicated and extended, such findings have clear implications for the pathophysiological relationship between early life stress and subsequent vulnerability to major depression.

The contrast between the effects of stress on the amygdala and those on the hippocampus and PFC is striking. Whereas acute and chronic stress impair hippocampal function, reduce the length and complexity of CA3 dendrites, and impair neurogenesis, very similar treatments lead to enhanced amygdala-dependent fear learning, increased length and complexity of amygdalar dendrites, and increased amygdala size. This contrast makes it clear that the well-documented effects of stress on hippocampal morphology and function are not manifestations of a universal effect of stress hormones or other aspects of stress on neuronal integrity. Rather, the effects of stress on brain morphology and function are region and circuit dependent. Both acute and chronic stress can have very different effects of different brain regions and functions, a fact with profound implications for our understanding of the pathophysiology of major depression.

\section{Ventral Striatum: Stress-Associated Changes in Neuroplasticity and the Mechanisms of Reward}

A final structure in which neuroplasticity may relate to effects of stress and the symptoms of depression is the ventral striatum, including the nucleus accumbens. The accumbens has a central role in the mechanisms of natural reward; as such, its dysregulation in depression is thought to relate to symptoms of anhedonia (Dunn et al, 2002; Nestler and Carlezon, 2006). A recent neuroimaging study 
supports this view, finding attenuated accumbens activation in response to positive visual stimuli in depressed subjects (Epstein et al, 2006). The relevance of such dysfunction, both to pathophysiology and to future therapies, was dramatically demonstrated by the successful treatment of several cases of profoundly refractory depression by deep brain stimulation of the nucleus accumbens (Schlaepfer et al, 2007).

Stress can activate the dopaminergic projection to the accumbens from the VTA; this may contribute to a homeostatic response to stress or to adaptive stress-related learning. However, chronic stress can cause long-term adaptations in the VTA-accumbens pathway (Ortiz et al, 1996; Saal et al, 2003) that may contribute to its dysregulation in major depression (reviewed in Nestler and Carlezon, 2006). Though plasticity in this pathway under conditions of stress and depression remains sparsely studied, it is likely to represent an important component of any comprehensive view of the relationship between stress, depression, and neuroplasticity.

\section{MOLECULAR AND CELLULAR MECHANISMS OF NEUROPLASTICITY}

The mechanisms of synaptic and morphological plasticity have been extensively studied in the context of their contribution to learning and memory (Malenka and Bear, 2004; Citri and Malenka, this volume). It is here that some of the most striking parallels between the mechanisms of neuroplasticity and those underlying MDD emerge, especially in the overlap between the cellular mechanisms of synaptic plasticity and the molecular and cellular changes that attend antidepressant treatment. A dizzying array of molecular components has been implicated in synaptic plasticity in various systems (Sanes and Lichtman, 1999); it is not our intention to comprehensively review this vast literature. Rather, we emphasize some of the common themes in studies of synaptic and structural plasticity, and some of the specific molecular players most cogent to a subsequent discussion of the mechanisms of antidepressant response.

\section{Inducers and Local Mechanisms of Synaptic Plasticity}

Mechanistically distinct forms of experimentally induced synaptic plasticity have been described in a number of different systems (Malenka and Bear, 2004). A common theme is that many forms of synaptic potentiation are triggered by increases in synaptic calcium influx and in the local concentration of the second messenger molecule cyclic AMP (cAMP). These pathways are particularly well suited to the requirements of a plasticity-inducing mechanism. Local calcium influx, for example, commonly derives from the NMDA receptor, which is a highly evolved coincidence detector-it is activated only when presynaptic and postsynaptic cells are depolarized simultaneously. Such coincidence detection is precisely what is required for many forms of homosynaptic plasticity (Hebb, 1949). cAMP is regulated by many modulatory neurotransmitters, including serotonin, dopamine, and norepinephrine, as well as by calcium; it is therefore optimally suited for the integration of synaptic events with the modulatory influences of global variables such as arousal and attention.

Local elevations in calcium and cAMP induce events required for short-term synaptic plasticity. For example, the calcium-calmodulin-dependent kinase II (CaMKII), which is activated by local increases in calcium, is critical for early LTP. CaMKII has unique properties that make it well suited to a role in the induction of synaptic plasticity. Upon induction by a sufficient rise in the local concentration of calcium, it can phosphorylate itself. Autophosphorylated CaMKII is persistently active, even after calcium levels fall. This mechanism allows an inducing pulse of calcium to lead to more persistent activation of CaMKII, and thereby to activation of downstream processes that result in synaptic change (Lisman and Goldring, 1988).

Several other calcium-calmodulin kinases exist in neurons. CaMKIV, in particular, is prominent in the neuronal nucleus, where it is an important activator of regulated transcription factor such as CREB (Bito et al, 1996). Inhibition of CaMKIV impairs both long-lasting forms of LTP and long-lasting hippocampus-dependent learning (Kang et al, 2001). Calcium calmodulin-dependent kinases can thus contribute to both short-term and long-lasting neuroplasticity.

Both CaMKII and other kinases can phosphorylate the GluR1 subunit of the AMPA glutamate receptor and associated proteins. This phosphorylation both increases the number of AMPA receptors in the postsynaptic membrane (by triggering insertion of new AMPA receptors) and enhances the function of those receptors already inserted. Both mechanisms contribute to an enhancement of synaptic strength.

At the structural level, insertion of AMPA receptors can result in the activation of 'silent synapses' (Malenka and Nicoll, 1997). A silent synapse is a synaptic connection at which the postsynaptic membrane contains only NMDA receptors (Figure 3). Because of the NMDA receptor's coincidence detection properties, such a synapse is not activated by simple depolarization of the presynaptic cell. Upon the induction of LTP, AMPA receptors are inserted into the postsynaptic membrane at such a synapse, rendering it active upon subsequent single presynaptic impulses (hence no longer 'silent'). This unsilencing of silent synapses contributes to synaptic strengthening and appears to be a major mechanism of LTP.

\section{Transduction to the Nucleus}

While short-term changes in synaptic strength can be mediated by local events at the synapse, such as AMPA receptor phosphorylation and insertion into the postsynaptic membrane, longer-term changes require a broader coordination of cellular mechanisms - in particular, induction of genes and production of new protein (Nguyen et al, 1994). Upon sufficient local elevation of calcium and cAMP, therefore, signal transduction cascades are activated that transmit the inducing signal to the nucleus (Kandel, 2001). (Specific signaling molecules, such as kinases and phosphatases, can participate both in local, early events and in signaling to the nucleus and the transition to more 


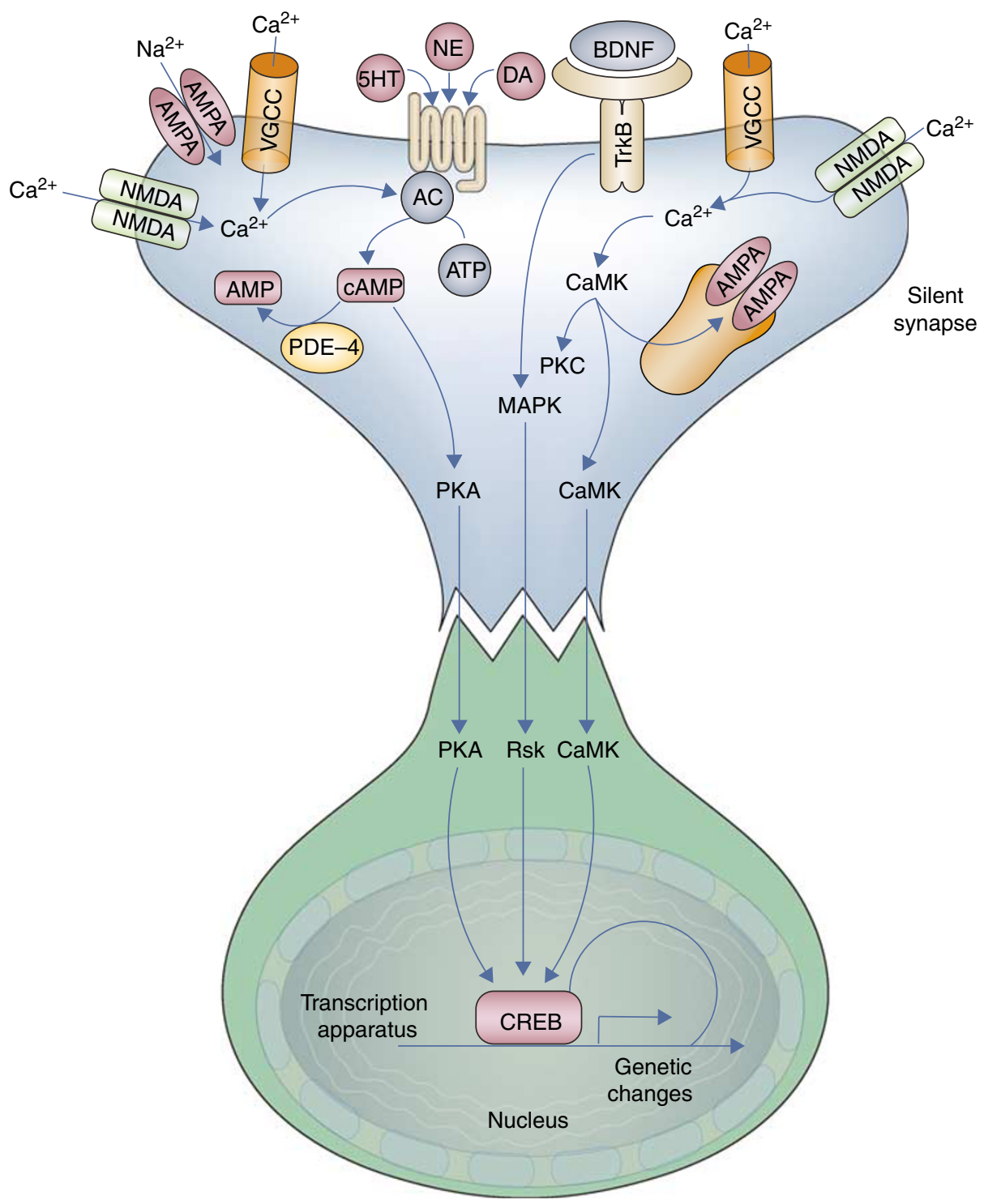

Figure 3 Major molecular pathways involved in neuroplasticity and affected by stress, depression, and antidepressant treatment. Some major molecular pathways involved in both short- and long-term neuroplastic changes are shown. Certain intermediates and other details are left out for clarity. Many of these pathways are influenced in opposite ways by stress and depression. For example, both chronic stress in animals and depression in humans have been associated with reductions in the transcription factor CREB, and antidepressants enhance CREB activity in the hippocampus. See text for further details and references. Abbreviations: NMDA, N-methyl-D-aspartate glutamate receptor; AMPA, amino-3-hydroxy-5-methyl-isoxazole-4-propionic acid glutamate receptor; VGCC, voltage-gated calcium channel; 5-HT, 5-hydroxytryptamine (serotonin); NE, norepinephrine; DA, dopamine; BDNF, brain-derived neurotrophic factor; Trk-B, BDNF receptor; AC, adenylyl cyclase; ATP, adenosine triphosphate; cAMP, cyclic adenosine monophosphate; AMP, adenosine monophosphate; PDE, phosphodiesterase; CaMK, calcium-calmodulin-dependent kinase; PKC, protein kinase C; MAPK, mitogen-activated protein kinase; PKA, protein kinase A; Rsk, ribosomal S6 protein kinase; CREB, CAMP response element-binding protein.

persistent forms of plasticity, as in the case of CaM kinases discussed above).

One signal transduction cascade that has been particularly clearly tied to the mechanisms of late-phase LTP (L-LTP) is the cAMP-dependent protein kinase, PKA (Abel et al, 1997). PKA consists of a regulatory and a catalytic subunit; at rest, the regulatory subunit binds to the catalytic subunit, inactivating it. Upon sufficient accumulation of cAMP, the two subunits dissociate, freeing the catalytic subunit to phosphorylate a variety of substrates. Since cAMP is increased by $\beta$-adrenergic, 5 -HT4, 6, 7, and dopamine D1 receptors, activation of PKA represents a mechanism by which modulatory neurotransmitters can influence the mechanisms of long-lasting synaptic plasticity.

Another signal transduction pathway that has been repeatedly implicated in signaling to the nucleus and the induction of L-LTP is the mitogen-activated protein kinase (MAPK) pathway. This cascade of kinases is critical for the induction of long-lasting synaptic plasticity in the hippocampus, amygdala, and cortex (Atkins et al, 1998; Huang et al, 2000; Di Cristo et al, 2001; reviewed in Giovannini, 2006). MAPK translocates to the nucleus upon induction of L-LTP, where it can activate nuclear substrates (Patterson et al, 2001). 
The induction of new genes in support of L-LTP requires that such signaling systems activate regulated transcription factors in the nucleus. There are likely to be many such regulated transcription factors involved in coordinating the genes that contribute to long-lasting synaptic change. Particularly, strong evidence implicates the transcription factor CREB in the regulation of numerous forms of synaptic change: it is activated upon synaptic stimulation and after learning in the hippocampus, amygdala, and cortex; and CREB inhibition in these and other brain regions disrupts LTP and corresponding forms of longlasting memory (Glazewski et al, 1999; Pittenger et al, 2002, 2006; Kida et al, 2002; reviewed in Carlezon et al, 2005). CREB can be activated by a variety of kinases, including PKA and (indirectly) the MAPK cascade.

\section{Effector Genes - Neurotrophins and Structural Change}

CREB, and other inducible transcription factors, induce effector genes that contribute to the stabilization of synaptic plasticity (Kandel, 2001). Prominent among these is brainderived neurotrophic factor (BDNF), which is induced by LTP and has a critical role in stabilizing synaptic change (Patterson et al, 1992). Once again, this has been demonstrated in hippocampus (Patterson et al, 1996), amygdala (Rattiner et al, 2005), and cortex (Bartoletti et al, 2002). Knockout of BDNF is lethal because of its multiple developmental roles, complicating analysis of its role in learning and memory; but recent studies that have disrupted BDNF only in the adult animal indicate a critical role in information processing and storage (Monteggia et al, 2004; Heldt et al, 2007; reviewed in Pang and Lu, 2004).

BDNF acts by multiple mechanisms and influences both early and late phases of synaptic plasticity, in both the presynaptic and the postsynaptic cells. It acts, at least in part, via the MAPK signaling cascade, suggesting that this pathway plays multiple roles in the regulation of plasticity. Other growth factors have also been demonstrated to influence LTP, including vascular endothelial growth factor (VEGF; Cao et al, 2004). Like BDNF, VEGF activates the MAPK cascade and has been implicated in the actions of stress and antidepressant treatments, as will be further discussed below.

It has long been hypothesized that long-lasting synaptic change is likely to correspond to morphological change at potentiated (or depressed) synapses. In recent years, growth of new dendritic spines and enlargement of existing spines have been demonstrated after LTP-inducing synaptic stimulation (Engert and Bonhoeffer, 1999; Matsuzaki et al, 2004). As a neurotrophic factor, with a critical role in stabilizing neurons during development, BDNF is well equipped to participate in such changes. The same is true for other LTP-induced secreted factors such as the tissue plasminogen activator (Pang and $\mathrm{Lu}, 2004$ ) and cell adhesion molecules such as NCAM (Bukalo et al, 2004).

\section{Positive and Negative Regulators of Neuroplasticity}

As is expected of any important physiological process, synaptic potentiation and other forms of neuroplasticity are controlled by both positive and negative regulatory mechanisms (Abel et al, 1998). LTD may under some circumstances provide a homeostatic counterbalance to excessive synaptic potentiation (Tononi and Cirelli, 2006). Inhibitors of the signal transduction cascades that contribute to synaptic potentiation also provide a counterbalancing influence. Examples include phosphatases such as calcineurin (Malleret et al, 2001), which can antagonize signaling through the MAPK cascade, and phosphodiesterases, which break down cAMP and thus attenuate PKAmediated signaling and other cAMP-dependent processes (Barad et al, 1998).

Recent studies have revealed that the NMDA receptor, which is the canonical initiator and positive regulator of LTP, can have contrary effects depending on its subcellular localization. Specifically, while synaptically localized NMDA receptors can trigger LTP, positively regulate MAPK, CREB and BDNF, and contribute to long-lasting plasticity and cell survival, activation of extrasynaptic NMDA receptors has the opposite effects, inhibiting CREB activation and the production of BDNF (Hardingham et al, 2002). It has been proposed that robust activation of extrasynaptic NMDA receptors may be an important contributor to excitotoxic cell death (Hardingham and Bading, 2003). Imbalance between stimulation of synaptic and extrasynaptic receptors may contribute to pathological states, including depression (as will be further explored below; reviewed in Pittenger et al, 2007).

\section{Neurogenesis}

Contrary to long-standing dogma, clear evidence now demonstrates that new neurons are generated in the adult mammalian brain; neurogenesis is prominent in the dentate gyrus region of the hippocampal formation (Altman and Das, 1965; Kaplan and Hinds, 1977; Kempermann et al, 1997; reviewed in Ming and Song, 2005).

The specific functional role and relevance of these new neurons is less firmly established; but a link between neurogenesis and the learning-related functions of the hippocampus is an intriguing possibility. Several lines of evidence support such a functional link (Leuner et al, 2006). Some computational theories of hippocampal function predict a role for new neurons in hippocampus-dependent learning (Chambers et al, 2004). Performance in a hippocampus-dependent spatial learning task correlates with the number of new neurons in aged rats (Drapeau et al, 2003), suggesting a functional contribution to learning. Electrical activity has been shown to be coupled with neurogenesis in the hippocampus, suggesting a mechanism whereby recruitment of the hippocampus during learning may lead to the production and incorporation of new neurons into the circuit (Deisseroth et al, 2004).

Behavioral studies in animals in which neurogenesis has been experimentally perturbed lend support to the idea that the new cells play a critical causal role in some forms of hippocampus-dependent learning. Administration of a chemotherapeutic agent that kills dividing cells impairs step-down avoidance, which depends on the function of the hippocampus (along with other structures; Shors et al, 2001). Saxe et al (2006) found that ablation of new neurons impaired dentate gyrus LTP (as measured in vitro) and 
hippocampus-dependent contextual fear conditioning, but did not affect cued fear conditioning (which does not require the hippocampus). Data on the role of the new neurons in spatial learning are conflicting: Saxe et al (2006) found ablation of the new neurons to spare spatial learning in the Morris water maze, while others have found interference with neurogenesis to compromise spatial learning (Snyder et al, 2005). Further studies will be needed to clarify the role that new hippocampal neurons play in learning and memory.

Mechanisms initially implicated in the induction of LTP are likely also to be important in the regulation of neurogenesis. For example, activation of CREB promotes neurogenesis (Nakagawa et al, 2002a), and blockade of CREB function decreases neurogenesis (Nakagawa et al, $2002 a, b)$. Likewise, growth factors regulate both the proliferation (VEGF; Cao et al, 2004) and survival (BDNF; Sairanen et al, 2005) of new hippocampal neurons.

This outline of molecular pathways contributing to neuroplasticity is necessarily selective and incomplete. More thorough treatments are given elsewhere (Malenka and Bear, 2004; Citri and Malenka, this volume), although this literature is so vast that it has become virtually impossible to review comprehensively. It does, however, lay the groundwork for an examination of how behavioral stress and pharmacological treatment with glucocorticoids alter signaling pathways associated with neuroplasticity.

\section{IMPACT OF STRESS ON THE MOLECULAR PATHWAYS OF NEUROPLASTICITY}

We have reviewed above some of the evidence that stress can lead to alterations in morphological plasticity: regression of dendrites, reduction in spine density, and a shrinkage of the neuropil in hippocampus and PFC. We now turn to effects of stress on some of the molecular mechanisms underlying neuroplasticity.

As noted above, acute and chronic stress can have quite different effects on learning: while acute stress can potentiate learning (and LTP; Shors, 2001), chronic stress leads to deficits in hippocampus-dependent memory reminiscent of those seen in major depression. It is therefore to be expected that the downstream molecular changes resulting from stress or manipulations of stress hormones may depend sensitively on the intensity and duration of the stressor glucocorticoid excess. This issue has not yet been explored in sufficient experimental detail for firm conclusions to be drawn. In the brief review presented here, we merely point out evidence that stress and glucocorticoids, either acute or chronic, can influence mechanisms implicated in neuroplasticity, without attempting to draw firm conclusions about the specific functional consequences of specific alterations in plasticity mechanisms or about mechanistic distinctions that may exist between the effects of acute and chronic stress on these systems.

\section{Contributions of Glutamate to Neuronal Atrophy after Stress}

As reviewed above, chronic stress or elevations in glucocorticoids can lead to neuronal atrophy, especially to dendritic retraction in cells of the CA3 cell field and the mPFC. Convergent evidence suggests that glutamatergic excess is likely to contribute to this cell damage and even, in extreme cases, to cell death (Sapolsky, 2000, 2003). Acute stressors rapidly increase extracellular glutamate in the PFC (Bagley and Moghaddam, 1997). Glucocorticoid excess increases glutamate release in the CA1 region of the hippocampus (Venero and Borrell, 1999), and chronic behavioral stress increases extracellular levels of glutamate in the CA3 region (Lowy et al, 1993). Glutamate antagonists can attenuate or block some of the effects of chronic glucocorticoid excess on dendritic morphology in the hippocampus (Magariños and McEwen, 1995). Exposure to glucocorticoids increases expression of the primary glial glutamate transporter, GLT-1 (Zschocke et al, 2005; Autry et al, 2006); this may serve to increase reuptake of elevated extracellular glutamate in conditions of chronic stress.

The finding of elevated extracellular glutamate in conditions of chronic stress is, at first blush, at odds with the suggestion that chronic stress attenuates mechanisms of neuroplasticity. This apparent contradiction is perhaps clarified by the recent distinction between the function of synaptic and extrasynaptic NMDA receptors (Hardingham et al, 2002; Hardingham and Bading, 2003). Stress-induced increases in extrasynaptic glutamate may perturb the balance between synaptic and extrasynaptic NMDA tone and have a net inhibitory effect on the mechanisms of synaptic plasticity and neuronal growth and survival (reviewed in Pittenger et al, 2007).

The effects of chronic stress on glutamatergic neurotransmission can be seen in alterations in the expression of glutamate receptor genes. For example, glucocorticoids can enhance AMPA-mediated excitatory synaptic transmission (Karst and Joëls, 2005). This contrasts with the finding that maternal separation stress has been shown to lead to lasting reduction in the expression of the NMDA receptor subunit NR2B and of the AMPA receptor subunits GluR1 and GluR2 (Pickering et al, 2006); differences in the level and chronicity of stress or glucocorticoid exposure may explain these contrasting results, which merit further study.

\section{Stress-Induced Alterations Plasticity-Associated Signaling Pathways}

Stress can alter neuronal signaling in multiple ways. Scattered observations in the literature suggest that chronic stress can alter signaling pathways implicated in synaptic plasticity. For example, several forms of chronic stress have been observed to increase the phosphorylation of MAPK (Pardon et al, 2005; Lee et al, 2006). Acute glucocorticoid treatment likewise induces the phosphorylation of MAPK (Revest et al, 2005), and acute swim stress leads to the phosphorylation of both MAPK and CaMKII (Ahmed et al, 2006). This activation of MAPK appears to be critical for the effects of behavioral stress on hippocampal LTP (Yang et al, 2004).

Both acute and chronic stressors can also lead to increased phosphorylation of CREB in the hippocampus (Pardon et al, 2005; Ahmed et al, 2006), consistent with an alteration in signaling pathways linking synaptic activity to nuclear effects. In contrast, chronic glucocorticoid treatment impairs CREB activity in cultured neurons (Focking 
et al, 2003); certain chronic mild stress paradigms have been reported to produce a similar effect (Grønli et al, 2006). Again, these contrasting results may relate either to differences in experimental paradigm (Nair et al, 2007) or to a central role for the intensity or duration of stressors on the downstream molecular perturbations that result.

\section{Stress Regulation of Growth Factors}

As noted above, signaling pathways implicated in neuroplasticity target, among other downstream targets, genes for growth factors such as BDNF. Both acute and chronic stress lead to reductions in hippocampal BDNF mRNA levels, suggesting an impairment of some of the mechanisms of neuroplasticity (Nibuya et al, 1995, 1999; Smith et al, 1995; Russo-Neustadt et al, 2001; Rasmusson et al, 2002; Franklin and Perrot-Sinal, 2006). Glucocorticoids likewise suppress BDNF expression (Smith et al, 1995; reviewed in Schaaf et al, 2000).

Other growth factors are likewise regulated by stress. For example, nerve growth factor, the paradigmatic developmental neurotrophin, has been reported to be upregulated by chronic stress (Alfonso et al, 2006). VEGF, a trophic factor induced by electroconvulsive seizure (Newton et al, 2003), is suppressed by chronic stress (Heine et al, 2005). Similarly, VEGF's angiogenic actions are impaired by glucocorticoid treatment (Kasselman et al, 2007). The involvement of trophic factors beyond BDNF suggests that a multifaceted machinery of neuronal support may be impaired by stress and, possibly, enhanced by antidepressant therapies (Newton and Duman, 2004).

\section{Other Downstream Target Genes}

Recently, gene profiling of animals exposed to stress has identified other genes that are differentially regulated by stress or glucocorticoids (Alfonso et al, 2004); many genes so identified have roles in neuroplasticity. For example, one study found decreases in the cell adhesion molecule NCAM (whose upregulation is critical for long-lasting LTP; Muller et al, 1996), the signaling molecule PKC- $\alpha$, and the synaptic marker synapsin I in various chronic stress models (Alfonso et al, 2006). Further characterization of neuroplasticityrelated genes dysregulated by different stressors will provide opportunities to identify which particular neuroplasticity-related mechanisms are most closely associated with the effects of acute and chronic stress in the brain.

\section{ANTIDEPRESSANTS INDUCE NEUROPLASTICITY}

If the effects of stress on the mechanisms of neuroplasticity contribute to the pathophysiology of depression, then antidepressant treatments might be expected to affect the same mechanisms. Substantial evidence suggests that this is in fact the case. In the simplest scenario, where chronic stress impairs the mechanisms of neuroplasticity, antidepressants would be predicted to have the opposite effect and enhance them. There are multiple situations in which this is in fact the case. Other instances are likely to be more complicated, as stress and antidepressant treatment impact the complicated and interacting mechanisms of neuroplasticity in contrasting but not directly opposite ways. A deepened appreciation of these interactions will inform our evolving understanding of the pathophysiology of depression and the mechanisms of antidepressant action, and is likely to guide the search for novel antidepressant strategies in the future.

\section{Enhanced Neuroplasticity and Cognitive Function with Treatment in Depressed Patients}

If depression entails a deficit in neuroplasticity, then antidepressant treatments may enhance neuroplasticity and even reverse deficits produced during the symptomatic period. Few studies to date have examined the effect of antidepressant therapies on cognition in normal human subjects, in part simply because of the ethical difficulties that would attend administration of chronic antidepressant therapy to patients who are not ill. One recent double-blind study suggested improvement in memory and a variety of other cognitive domains with chronic fluoxetine treatment in elderly patients with mild cognitive impairment (Mowla et al, 2007). Given the mounting evidence that antidepressant treatment can promote neuroplasticity, further studies of this sort, using antidepressants with a primary goal of enhancing impaired cognitive function, may be warranted.

A small literature does address the improvement of cognitive deficits, and even of structural damage, in patients treated with a variety of antidepressant therapies. Electroconvulsive therapy (ECT) is perhaps the most efficacious antidepressant therapy (and, incidentally, the one with the most profound effects on the mechanisms of neuroplasticity). Examination of cognitive improvement in patients receiving ECT is complicated by the fact that memory difficulties, especially retrograde amnesia, are a clear side effect of the treatment (Sackeim, 2000). However, many patients show clear cognitive improvement, even shortly after treatment (Sackeim et al, 1992).

A few studies likewise show improvement in memory and other cognitive functions in depressed patients after pharmacological treatment. An early study found improvement in memory with treatment with the monoamine oxidase inhibitor (MAOI) moclobemide, which was superior to that of the adrenergic agonist viloxazine or the tetracyclic antidepressant maprotiline (Allain et al, 1992). The lack of anticholinergic effects of moclobemide was cited as a potentially important contributor to this difference; the anticholinergic effects of many older antidepressants, especially the tricyclics, may worsen cognitive function and mask any improvement produced by improvement of depression or enhancement of neuroplasticity. A more recent study found improvements in verbal memory after treatment of depressed patients with fluoxetine (Vythilingam et al, 2004); another found improvements in memory and attention in patients with late-onset depression after treatment with either fluoxetine or reboxetine (Gallassi et al, 2006). The absence of a placebo-treated control group makes it problematic to assign a causal role to the pharmacological treatment in these studies. More studies of the improvement in memory and other cognitive functions that may attend antidepressant treatment are clearly warranted. 
As described above, stress can lead to atrophy of both hippocampus and PFC; morphological change in both regions is seen in patients with depression (MacQueen et al, 2003; Stockmeier et al, 2004). An ideal antidepressant treatment would both prevent this atrophy and, by stimulation of neurotrophic mechanisms, reverse it once it has occurred. No large longitudinal studies have been reported that might evaluate the ability of currently available antidepressants to accomplish this. Some studies examining hippocampal volume in patients with a long history of depression find a correlation with the amount of time spent symptomatically ill, suggesting that successful treatment and symptom reduction may halt a deteriorative process (Shah et al, 1998; Sheline et al, 1999; MacQueen et al, 2003). However, other studies have not found such a correlation (Bremner et al, 2000). There is one report that antidepressant treatment reverses the hippocampal volume reduction in PTSD patients and improves declarative memory (Vermetten et al, 2003). Additional longitudinal studies will be required to further examine the effects of antidepressant treatment on hippocampal volume in subjects with MDD.

\section{Antidepressants Enhance Learning and Memory in Animal Models}

Investigations of the effect of antidepressants on LTP have produced mixed results, with some studies reporting increases in LTP with antidepressant treatment, some decreases, and some with no effects. However, closer examination, comparing effects in subfields of hippocampus (ie dentate gyrus $v s$ CA1 pyramidal cell layer) and/or types of antidepressants (tricyclic $v s$ nontricyclic SSRIs), reveals more consistency.

In the dentate gyrus, where high-frequency stimulation of the perforant pathway projection to granule cells is used to stimulate LTP, both chronic ECS and chemical antidepressant treatment increase LTP (Stewart and Reid, 2000; Levkovitz et al, 2001). One of these studies (Stewart and Reid, 2000) found that chronic ECS or SSRI (fluoxetine) administration increases baseline field potentials in the dentate gyrus. In vitro LTP was reduced; this was interpreted as representing a ceiling effect, resulting from prior induction of plasticity by ECS or fluoxetine. The other study reports that either desipramine or mianserin administration results in increased LTP of dentate gyrus (Levkovitz et al, 2001). It is interesting to speculate that this increased potential for plasticity in the dentate could result from an increased number of newborn granule cells, which are known to have greater potential for neuroplasticity (Toni et al, 2007; Tashiro et al, 2007).

In contrast, most early studies of CA1 pyramidal cells report that chronic antidepressant treatment decreases LTP (Massicotte et al, 1993; O'Connor et al, 1993; Von Frijtag et al, 2001). However, these early studies were limited to tricyclic antidepressants (ie imipramine, triimipramine), which have substantial anticholinergic properties that could oppose other effects on plasticity. More recent reports, using antidepressant medications with less anticholinergic effect, have suggested that chronic administration of an SSRI or an atypical antidepressant (tianeptine) increases LTP and blocks the stress-induced impairment of LTP and enhancement of LTD in CA1 (Vouimba et al, 2006; Holderbach et al, 2007). Chronic SSRI administration has been reported to have similar effects on hippocampal-PFC circuits, reversing a stress-induced impairment of LTP and enhancement of LTD (Rocher et al, 2004). Together these studies indicate that chronic antidepressant treatment increases cellular plasticity in the dentate gyrus, and there is some evidence that SSRI antidepressants have a similar effect in on CA1, as well as block the effects of stress on this subpopulation of hippocampal neurons.

Much less is known about the influence of antidepressant treatments on behavioral models of learning and memory. Chronic administration of fluoxetine or venlafaxine, a mixed action reuptake inhibitor, is reported to improve performance in the Morris water maze, a spatial learning and memory model (Nowakowska et al, 2000, 2003, 2006), although another study found that fluoxetine did not influence performance in this task (Stewart and Reid, 2000). Chronic imipramine or tianeptine were not effective in the Morris water maze (Nowakowska et al, 2000, 2003), although another study found that chronic amitriptyline prevents age-induced impairments in learning and memory (Yau et al, 2002). This latter study also found a decrease in circulating corticosterone levels in antidepressant-treated rats that could contribute to the observed improvement in learning and memory. Tianeptine, but not fluoxetine, has been reported to improve discrimination performance in a radial maze task (Jaffard et al, 1991). Finally, chronic imipramine, but not paroxetine, has recently been reported to impair spatial working memory in a radial arm maze task (Naudon et al, 2007). Clearly, additional studies are needed to further test the influence of different classes of antidepressants in a standardized manner on behavioral models of learning and memory to fully characterize the influence of these agents.

\section{Antidepressant Treatment Enhances Structural Plasticity and Neurogenesis}

Increasing evidence suggests that, in addition to enhancing functional neuroplasticity, antidepressants produce structural plasticity. This is observed at several different levels, including numbers of synapses, spines, dendrites, and even numbers of cells.

At the smallest scale, antidepressant treatment has been reported to increase the number of synapses, determined by electron microscopy (Hajszan et al, 2005). This study examined the influence of fluoxetine administration of different durations in ovariectomized rats. As few as 5 days of fluoxetine treatment increases the number of synapses in the CA1 pyramidal cell layer, while longer treatment (14 days) also produced a similar increase in the CA3 pyramidal cell layer. Another study found that chronic administration of a tricyclic antidepressant (amitriptyline) blocked the decrease in spine density in dentate gyrus, CA3 and CA1 cell layers that results from olfactory bulbectomy, a widely used model of depression-like behaviors (Norrholm and Ouimet, 2001; in this study, amitriptyptyline alone did not produce an increase in spine density). Although still preliminary, these labor-intensive studies provide evidence for altered structural plasticity at the levels of both synapse and spine density. 
More studies have also been conducted at the level of dendritic morphology in the hippocampus. As described above, McEwen and colleagues have demonstrated that chronic stress (intermittent daily immobilization for 3 weeks) decreases the number and length of apical dendrites of CA3 pyramidal cells in the hippocampus (Watanabe et al, 1992; McEwen, 1999). This reduction in dendritic length and complexity is blocked or reversed by chronic administration of an atypical antidepressant (tianeptine), but not by a typical SSRI (fluoxetine; Magariños et al, 1999). Additional studies are needed to further test the influence of different classes of antidepressants on dendrite morphology in the hippocampus, both alone and in conjunction with exposure to stress.

Another level of structural plasticity that has received a great deal of attention is the regulation of new cell birth or neurogenesis in the hippocampus. These studies demonstrate that chronic antidepressant administration increases neurogenesis in the adult hippocampus (Malberg et al, 2000; reviewed in Warner-Schmidt and Duman, 2006). The increase in neurogenesis is observed with different classes of antidepressants, including SSRIs, selective norepinephrine reuptake inhibitors (SNRIs), MAOIs, atypical antidepressants, and ECS. The neurogenic action of antidepressants requires chronic treatment (14-21 days), with the exception of ECS, which increases neurogenesis 3 days after a single seizure. Antidepressants increase different aspects of neurogenesis, including the rate of proliferation (Malberg et al, 2000) and the survival of newborn neurons (Nakagawa et al, 2002a). Activation of the CAMP-CREB cascade increases neurogenesis, implicating this pathway in the neurogenic actions of antidepressants (Nakagawa et al, 2002b). BDNF is also required for antidepressant regulation of the survival of newborn neurons, though not the proliferation (Sairanen et al, 2005).

Establishing the causal role of neurogenesis in the behavioral actions of antidepressants has been challenging, as it is technically difficult to functionally perturb the new neurons without simultaneously disrupting other aspects of behavior or hippocampal function. Evidence to date, however, suggests that the induction of neurogenesis is required for antidepressant action. A casual role for neurogenesis in behavioral change requires that a response to antidepressants be dependent on chronic treatment, because it takes several weeks for newborn neurons to differentiate and mature into functional neurons; such a delayed mechanism of action is consistent with the typical delayed therapeutic response to antidepressants. Two paradigms that are dependent on long-term antidepressant administration are novelty-suppressed feeding and chronic unpredictable stress. These models differ from other standard antidepressant screening paradigms, such as the forced swim and tail suspension tests that respond to acute or short-term antidepressant treatments. An initial study found that blockade of cell proliferation by irradiation blocked the actions of antidepressants in noveltysuppressed feeding and chronic unpredictable stress paradigms (Santarelli et al, 2003). In addition, 5-HT1A mutant mice, in which SSRI induction of neurogenesis is blocked, show an attenuated antidepressant response (Santarelli et al, 2003). Recent studies using another a genetic model to ablate cells that express GFAP, which includes neural precursors, have confirmed these effects (Rene Hen, personal communication).

\section{Effects of Antidepressant Treatment on Glutamatergic Neurotransmission}

Just as stress has been found to alter glutamatergic neurotransmission in ways that can contribute to neuronal atrophy and even cell death (Sapolsky, 2000, 2003), antidepressant treatments can modulate glutamate neurotransmission in neuroprotective ways. Indeed, agents that directly modulate neurotransmission hold promise as novel antidepressants (reviewed in Bleakman et al, 2007; Pittenger et al, 2007; Witkin et al, 2007).

Several lines of evidence suggest that established antidepressants can directly modulate glutamatergic neurotransmission. For example, tricyclic antidepressants directly block the NMDA receptor pore at micromolar concentrations (Reynolds and Miller, 1988). Chronic antidepressant treatment alters the conformation of the NMDA receptor, suggesting some form of longer-term compensatory change (reviewed in Paul and Skolnick, 2003). Such actions of antidepressants on the NMDA receptor may represent a mechanism whereby they can influence the mechanisms of neuroplasticity at the synaptic level.

Antidepressant drugs can also affect AMPA receptor trafficking. The investigational antidepressant riluzole, which was developed for the treatment of amyotrophic lateral sclerosis (Miller et al, 2007) but has recently been found to hold promise in the treatment of depression (Zarate et al, 2004; Sanacora et al, 2007), illustrates this point particularly well. Riluzole reversibly attenuates AMPA-mediated synaptic currents in cultured cells (Albo et al, 2004). Both rilulzole and the anticonvulsant lamotrigine, which also has antidepressant properties, increase the surface expression of AMPA subunits GluR1 and GluR2, suggesting an effect on the regulated AMPA receptor trafficking that underlies the conversion of silent to active snapses (Du et al, 2007). More conventional antidepressants, such as fluoxetine, can regulate the phosphorylation state and thereby the function of AMPA receptors (Svenningsson et al, 2002). These effects of antidepressants that target other molecules and pathways have led to the proposal that direct modulators of AMPA function, or AMPAkines, can function as antidepressants; and substantial evidence supports this idea (reviewed in Witkin et al, 2007).

A striking recent finding that emphasizes the interaction between antidepressants and glutamatergic neurotransmission is the rapid antidepressant effect of the NMDA antagonist ketamine. This startling effect was first observed in a small study designed to test the psychotomimetic properties of ketamine in depressed patients (Berman et al, 2000 ) and was more recently replicated in a larger study (Zarate et al, 2006). As in the case of increased glutamate after chronic stress, this effect is initially counterintuitive: NMDA activation is trophic and enhances neuroplasticity, so NMDA blockade might be expected to worsen cellular damage. Two observations may make sense of this apparent conundrum. As noted above, synaptic and extrasynaptic NMDA receptors have contrasting effects on neuroplasticity and cellular survival. It is likely that subanesthetic doses of 
an NMDA antagonist have a preferential effect on extrasynaptic NMDA receptors, both because the higher-affinity NR2B-containing receptors may be more prevalent in the extrasynaptic space and because the ambient glutamate concentration with which the NMDA antagonist must compete is much lower. In addition, in vivo evidence from rats suggests that, again at subanesthetic concentrations, ketamine may preferentially block NMDA receptors on GABAergic interneurons and thereby paradoxically increase synaptic glutamate tone, at least in the frontal cortex (Moghaddam et al, 1997). This possibility is supported by the observation that NMDA receptor antagonists increase the expression of BDNF, and activity-dependent gene expression (Metsis et al, 1993), and increase adult hippocampal neurogenesis (Gould and Cameron, 1997). Appropriately dosed ketamine may therefore simultaneously decrease activation of extrasynaptic NMDA receptors and enhance glutamate tone at synaptic NMDA receptors, producing a net pro-neuroplasticity effect (reviewed in Pittenger et al, 2007).

\section{ANTIDEPRESSANTS INCREASE NEUROPLASTICITY-RELATED SIGNALING PATHWAYS}

Overlap between the molecular actions of synaptic plasticity and those targeted by antidepressants provided some of the earliest and strongest evidence for mechanistic overlap between the two phenomena. These studies demonstrate that some of the key signaling components identified as critical regulators of LTP and synaptic plasticity are also regulated by antidepressants and are required for the cellular and behavioral actions of antidepressant treatments.

\section{Antidepressants Upregulate the cAMP-PKA-CREB Cascade}

Evidence from a number of different studies has demonstrated that antidepressant treatments upregulate the cAMP signal transduction pathway. This includes increased levels of $\mathrm{G} \alpha$ s coupling to adenylyl cyclase in the hippocampus and frontal cortex and resulting elevation of cAMP production in response to chronic administration of different classes of antidepressants (reviewed in Donati and Rasenick, 2003). Levels of PKA are also reported to be upregulated by chronic administration of different classes of antidepressants, including tricyclics, MAOIs, and ECS (Nestler et al, 1989; Perez et al, 1989). Levels of PKA are increased in particulate fractions, and subcellular fractionation studies demonstrate increases in both the nuclear (Nestler et al, 1989; Tiraboschi et al, 2004b) and microtubule fractions (Perez et al, 2000). The increases in nuclear PKA levels are more consistent with SNRI than SSRI antidepressants, and vary somewhat depending on the brain region examined (PFC vs hippocampus) and type of enzyme activity (basal $v s$ cAMP-stimulated) in different studies.

Studies demonstrating an increase in nuclear levels of PKA also suggest that the actions of antidepressant treatments could involve the regulation of transcription factors, such as CREB. Early studies provided support for this hypothesis, demonstrating that chronic administration of different classes of antidepressants, including SSRI and SNRI agents, MAOIs, and ECS, increases the expression and function of CREB in the PFC and hippocampus (Nibuya et al, 1996; Frechilla et al, 1998; for reviews see Tardito et al, 2006; Blendy, 2006). These studies demonstrate that chronic, but not acute, antidepressant treatment increases levels of CREB mRNA and immunoreactivity, as well as levels of CRE binding in the hippocampus. Subsequent studies have also demonstrated that the phosphorylation and transcriptional activity of CREB is increased by chronic antidepressant treatment (Thome et al, 2000; Tiraboschi et al, 2004b). Analysis of CREB and nuclear localization of several protein kinases in the same study indicates that PKA is less likely to account for the induction of CREB phosphorylation than CAMKIV and MAPK, although a role for PKA cannot be completely excluded (Tiraboschi et al, 2004b).

Regulation of CREB is likely to be important in antidepressant responses in experimental animals. Viral expression of CREB in the hippocampus produces antidepressant effects in behavioral models of despair and antidepressant response, including the forced swim test and learned helplessness model (Chen et al, 2001a, b). Studies of mutant mice have reported that CREB hypomorphic mice have normal antidepressant responses in the FST (Conti et al, 2002); this discrepancy may result, in part, from adaptive changes in these knockout mice from partial CREB knockout throughout the brain and throughout development. Drugs that more directly activate the cAMP-CREB cascade, such as the cAMP-specific phosphodiesterase type IV (PDE4) inhibitor rolipram, produce antidepressant effects in behavioral models (reviewed in O'Donnell and Zhang, 2004). The cAMP-CREB cascade also increases adult hippocampal neurogenesis (Nakagawa et al, 2002a,b), which, as described above, has been implicated in the actions of antidepressant treatment (Santarelli et al, 2003; Duman, 2004).

In humans, there may be a link between genetic polymorphisms in the CREB gene and major depression (Zubenko et al, 2003). A recent study also suggested an association between a CREB polymorphism and anger expression (which may relate to suicide risk) in men with depression (Perlis et al, 2007). Post-mortem studies suggest that reduced $\mathrm{CREB}$ function may contribute to clinical depression, and that its upregulation may also be an important component of antidepressant response in humans. CREB expression in temporal cortex is decreased in depressed suicide subjects (Dowlatshahi et al, 1998; Odagaki et al, 2001; Dwivedi et al, 2003); CREB phosphorylation has also been reported to be reduced in postmortem tissue (Yamada et al, 2003). In addition, CREB is upregulated by pre-mortem antidepressant treatment in post-mortem tissue (Dowlatshahi et al, 1998), as well as in blood platelets (Koch et al, 2002). While post-mortem studies such as these are particularly challenging, they provide critical evidence that mechanisms elucidated in experimental animals, such as the role of CREB in the antidepressant response, are of clinical relevance in human patients.

These studies provide convincing evidence that the CAMP-PKA-CREB cascade is regulated by antidepressant treatment, and that activation of this pathway can produce 
an antidepressant response in behavioral models. The evidence linking these effects to synaptic plasticity is less robust. As described above, the cAMP-PKA-CREB pathway has a central role in many forms of neuroplasticity, and antidepressants can enhance LTP and memory; but this argument for a role for CREB-mediated neuroplasticity is circumstantial. No studies to date have directly tested the role of this pathway in the actions of antidepressants, and future studies will be required to test this hypothesis.

\section{Antidepressants Regulate CaMKII}

A number of studies have investigated the regulation of CaMKII by antidepressants. Several studies have reported that chronic, but not acute, antidepressant treatment increases CaMKII enzymatic activity in neuronal cell bodies of the hippocampus, due to an increase in autophosphorylation of CaMKII at $\mathrm{Thr}^{286}$ (Popoli et al, 1995; Celano et al, 2003; Tiraboschi et al, 2004a). As described above, phosphorylation at this site leads to $\mathrm{Ca}^{2+}$-independent activation of CaMKII and therefore extended enzymatic activity. Subsequent studies demonstrate that there is also an increase in CAMKII expression, enzymatic activity, and phosphorylation in synaptic vesicles of the hippocampus and PFC after antidepressant treatment (Celano et al, 2003), but a decrease in phosphorylation of CaMKII in synaptic terminals and synaptic membranes (Bonanno et al, 2005). This apparent contradiction has been resolved by a recent study from the same group, demonstrating that antidepressant treatments (with either an SSRI or an SNRI) cause a redistribution of CaMKII from synaptic membranes to vesicles and a corresponding decrease in membraneassociated synapsin I (Barbiero et al, 2007). Since vesicles localized with the synaptic membranes are closely related to the readily releasable pool of glutamate, this redistribution suggests that antidepressant treatment reduces the potential for glutamate release. This is supported by a functional study demonstrating that depolarization-induced release of glutamate is decreased (Bonanno et al, 2005).

If this interpretation is correct-that modulation of CaMKII by antidepressants leads to a net decrease in synaptic release of glutamate-antidepressant treatment would decrease the potential for synaptic plasticity, at least via this mechanism. While a reduction in membraneassociated synaptic vesicles could decrease the overall release of glutamate, the resulting effect could be to increase the signal-to-noise ratio such that only salient stimuli lead to synaptic plasticity-related changes in the hippocampus and PFC. An enhanced signal-to-noise ratio may be further enhanced by potentiation of other mechanisms contributing to plasticity through alterations in downstream postsynaptic mechanisms such as cAMP-mediated and MAPK signaling (as reviewed above and below, respectively). Alternatively, the reported upregulation of CAMKII in cell bodies, as opposed to presynaptic terminals, could lead to other types of synaptic plasticity and neuroprotection that also contribute to the actions of antidepressant treatments.

\section{Antidepressants Upregulate the MAPK Cascade}

As reviewed above, the MAPK cascade has also been implicated in some forms of long-lasting neuroplasticity.
The MAPK pathway is also activated by BDNF and other neurotrophic factors. A number of reports suggest that antidepressants influence the expression or phosphorylation of the kinases in this pathway as well. One study found that chronic administration of different classes of antidepressants increases levels of ERK1 and ERK2 in total homogenates of hippocampus and PFC, although levels of phospho-ERK were not altered (Tiraboschi et al, 2004b). This study also reported increases in levels of phosphoERK $1 / 2$ in nuclear fractions, under some conditions, suggesting that ERK signaling may contribute to increased phosphorylation and activation of CREB. However, the situation may be more complicated than this; another study found that fluoxetine administration decreased levels of phospho-ERK1/2 in nuclear and/or cytosolic fractions of hippocampus and PFC, while imipramine increased levels of phospho-ERK in PFC only (Fumagalli et al, 2005). Interestingly, chronic administration of an atypical antipsychotic (olanzapine), which has antidepressant efficacy and increases the actions of SSRIs in clinical studies (Nemeroff, 2006), increases levels of ERK1 and ERK2 in PFC fractions (Fumagalli et al, 2006).

As in the case of the CAMP/CREB pathway, other lines of evidence suggest that MAPK modulation by antidepressant treatment is likely to play a causal role in the antidepressant response. Agents that inhibit the MAPK pathway increase behavioral despair and helplessness in the forced swim test and learned helplessness paradigms and block the effects of antidepressants in rodents (Duman et al, 2007). An earlier study found contrasting effects of MAPK inhibitors, but these effects may be explained by the acute locomotoractivating actions of these agents (Einat et al, 2003). Finally, post-mortem studies report that ERK activity and expression are decreased in depressed suicide subjects (Dwivedi et al, 2001). More recent studies have reported that ERK5 is also decreased in suicide subjects (Dwivedi et al, 2007) and that the upstream kinases responsible for activation of ERK are decreased (Dwivedi et al, 2006).

Taken together these studies indicate that antidepressants upregulate the MAPK pathway, opposing the actions of suicide/depression, and that blockade of the MAPK cascade results in despair/helplessness and inhibition of the antidepressant actions in behavioral models. However, there are also conflicting reports on antidepressant regulation of phospho-ERK1/2, depending on the brain region, subcellular fraction, and antidepressant tested.

\section{ANTIDEPRESSANTS UPREGULATE NEUROTROPHIC FACTOR EXPRESSION}

Another line of evidence supporting the hypothesis that antidepressant treatment leads to altered neuroplasticity is the regulation of neurotrophic factors by antidepressants. As described above, certain neurotrophic factors, such as BDNF, are regulated by activity; BDNF has been shown to be necessary and sufficient for induction of LTP and performance in some models of learning and memory (reviewed in Pang and Lu, 2004). Furthermore, BDNF is critical to numerous forms of neuroplasticity, and is reduced by chronic stress, as reviewed above. We now 
review the evidence that antidepressant treatment increases BDNF and other trophic factors.

\section{Antidepressant Treatment Increases the Expression of BDNF}

Chronic antidepressant administration increases the expression of BDNF in the hippocampus and PFC (Nibuya et al, 1995; reviewed in Duman and Monteggia, 2006); this effect contrasts with the inhibition of BDNF by chronic stress, as reviewed above. Increased expression of BDNF is observed with different classes of antidepressants, including SSRI, SNRI, MAOI, atypical agents, and ECS. The induction of BDNF is dependent on chronic treatment for 2-3 weeks and is pharmacologically specific: other types of psychotropic drugs do not increase BDNF in the hippocampus and PFC.

There have been a number of conflicting studies, reporting no change or even decreased BDNF expression. These discrepancies are most likely due to differences in the time course or dose of antidepressant tested, or the time after the last treatment (reviewed in Duman and Monteggia, 2006). Since BDNF expression is also decreased by stress and increased by neuronal activity, the individual experimental conditions (eg housing, treatment) are critical for the outcome of these studies.

Roles for BDNF in depression and antidepressant responses are supported by several additional lines of evidence. First, levels of BDNF are decreased in the brains of depressed patients and increased in patients receiving antidepressant treatment at the time of death (Chen et al, 2001b; Dwivedi et al, 2003; Karege et al, 2005). Surprisingly, levels of BDNF in serum of depressed subjects are also decreased; this decrease is reversed by antidepressant treatment, suggesting that it may prove to be a useful, relatively noninvasive biomarker of the depressed state (Karege et al, 2002; Shimizu et al, 2003; reviewed in Duman and Monteggia, 2006).

Second, BDNF infusions produce an antidepressant response in behavioral models, including the forced swim and learned helplessness paradigms (Siuciak et al, 1997; Shirayama et al, 2002; Hoshaw et al, 2005); and the response to antidepressant treatment is blocked in mice with forebrain-specific impairment of either BDNF or its receptor, TrkB (Saarelainen et al, 2003; Monteggia et al, 2004). Conditional BDNF mutant mice also display an increase in depression-like behavior in the forced swim and sucrose preference tests, although these effects are specific to female mice (Monteggia et al, 2007).

Third, a recent clinical study has reported that a BDNF polymorphism (val66met), when combined with the $S$ allele of the 5-HT transporter, increases the risk for depression in children exposed to trauma (Kaufman et al, 2006). The met allele decreases the processing and release of BDNF and has been linked to reduced episodic memory and hippocampal function in humans (Egan et al, 2003). The same allele produces a striking anxiety phenotype when introduced into mice (Chen et al, 2006).

Together, these studies provide strong support for the hypothesis that reduced BDNF expression contributes to depression-like behavior in animal models and may lead to similar effects in humans, and that antidepressant treatment increases or reverses this deficit. These findings are consistent with the hypothesis that BDNF-induced neuroplasticity contributes to the actions of antidepressants, although it is also possible that other BDNF actions (such as neuroprotection) also play a role.

\section{Antidepressant Treatment Increases the Expression of VEGF}

Recent studies have provided evidence that another trophic factor, VEGF, contributes to the actions of stress and antidepressant treatments. Previous studies have demonstrated that VEGF is regulated by neuronal activity and that VEGF increases hippocampal LTP and synaptic transmission (Cao et al, 2004). We have recently reported that chronic antidepressant administration, including SSRI, SNRI, and ECS, increases the expression of VEGF mRNA and protein in the hippocampus (Newton et al, 2003; Warner-Schmidt and Duman, 2007). As is the case with BDNF, this increase is opposite to the stress-induced decrease in VEGF expression in the hippocampus (Heine et al, 2005). VEGF infusions into the lateral ventricles increase neurogenesis and produce antidepressant responses in four different behavioral models, including those responsive to short- (forced swim and learned helplessness) and long-term antidepressant treatments (sucrose preference and novelty-induced hypophagia). In contrast, blockade of VEGF signaling through one of its receptors, VEGF-R2 (also known as Flk-1), blocked the behavioral and neurogenic effects of antidepressants in all four behavioral models (Warner-Schmidt and Duman, 2007).

The results of these studies suggest that VEGF is necessary and sufficient for the behavioral and neurogenic actions of antidepressants. Moreover, the results demonstrate that VEGF contributes to the actions of antidepressants in both short- and long-term responses. It is possible that the rapid effects of VEGF and antidepressants are mediated by regulation of neuroplasticity and synaptic transmission, while the more long-term effects occur via regulation of neurogenesis. Further studies will be required to more completely delineate the cellular mechanisms underlying the actions and interactions of VEGF and antidepressants.

It is striking that multiple neurotrophins have now been implicated in antidepressant action. Indeed, the list may not end here - there is evidence that insulin-like growth factor1 and fibroblast growth factor-2 are involved in stress, depression, and antidepressant responses (Duman and Monteggia, 2006). There are several possible explanations for this apparent redundancy. First, multiple trophic factors may provide redundancy for neuroplasticity and neuroprotection-critical neuronal functions. However, complete redundancy of the different factors is not supported by data, suggesting that BDNF and VEGF are individually necessary, not just sufficient, for antidepressant responses. It is possible that the different trophic factors exert different, complementary actions, in addition to functions that have some overlap. Additional studies will be needed to fully characterize the interactions of these neurotrophic/growth factor systems. 


\section{LIMITATIONS OF THE NEUROPLASTICITY HYPOTHESIS}

The neuroplasticity hypothesis suggests that impaired mechanisms of neuroplasticity are a core pathophysiological feature of MDD, that chronic stress is an important causal factor in the development of this impairment, and that antidepressant treatments act, at least in part, through mitigation of impaired mechanisms of plasticity. This hypothesis unifies much clinical and preclinical data, which we have sought to summarize above. However, the hypothesis also has important limitations.

One that has received attention recently is that alterations of neuroplasticity in certain brain regions produce a prodepressive effect. For example, expression of CREB in the nucleus accumbens increases behavioral despair and helplessness in the forced swim and learned helpless paradigms, and CREB inhibition has an antidepressant effect (Pliakas et al, 2001; Newton et al, 2002). Similarly, increased expression of BDNF in the mesolimbic dopamine system produces a pro-depressive effect in the forced swim test (Eisch et al, 2003) and social defeat stress models of depression (Berton et al, 2006). These studies indicate that neuroplasticity in the mesolimbic dopamine circuit can produce effects that are opposite to the antidepressant effects observed in the hippocampus.

Neuroplasticity in the amygdala may likewise work contrary to antidepressant effects, though here the argument is more circumstantial. Chronic stress and glucocorticoid treatment increase dendritic branching and synaptic connectivity in the amygdala, perhaps paralleling the increased size of the amygdala reported in some neuroimaging studies of depressed patients. It seems likely that these plastic events contribute to the development of a depressive state, rather than contributing to antidepressant response.

This suggestion raises the concerning possibility that novel therapeutic strategies aimed at the enhancement of neuroplasticity may have unintended pro-depressant effects through their impact on the nucleus accumbens or other structures outside the hippocampal system that has informed most of our discussion. Early studies suggest that the predominant effect of activating neuroplasticity-associated signaling systems is an antidepressant response. Systemic administration of rolipram, which activates the CAMP-CREB cascade, produces an antidepressant effect in behavioral models (O'Donnell and Zhang, 2004). Similarly, intraventricular infusions of BDNF produce an antidepressant response in the forced swim test (Hoshaw et al, 2005). Despite these promising results, further studies in a variety of behavioral models are needed to fully characterize the global effects of activation of neuroplasticity-associated pathways.

\section{RELEVANCE OF ENHANCEMENT IN NEUROPLASTICITY TO BEHAVIORAL MODELS OF DEPRESSION}

Although enhanced neuroplasticity is considered a desirable adaptation, the relationship with the actions of antidepressants is not readily interpretable. Are the enhancements in neuroplasticity we have reviewed part of an important pathway that contributes to antidepressant effects? Are they a consequence of altered mood state or homeostasis of modulatory neurotransmitters or hormone systems? Or is the association of enhanced neuroplasticity with antidepressant effect an epiphenomenon - suggestive of shared underlying mechanisms, perhaps, but not necessarily indicative of a causal relationship between the two phenomena?

The nature of the behaviors in rodents that are widely used to model aspects of depression and have proven validity for predicting antidepressant response may shed some light on this question. Most of the behaviors used to assay antidepressant effect in rodents-learned helplessness, the forced swim test, and the tail suspension test, for example- are models of behavioral despair and coping. Animals are placed in an adverse circumstance from which it is difficult or impossible to escape, and they enter a behavioral state of passivity in which they no longer attempt to do so. It may be that enhancements in neuroplasticity, and the corresponding increased capacity to adapt and learn, lead to an enhanced potential repertoire of behaviors or capacity to explore new escape options in these adverse circumstances, and thus reduces the tendency to enter such a state of behavioral despair. This interpretation predicts that enhanced neuroplasticity is, indeed, causally important for reduced depression-like behaviors, at least in models of behavioral despair. It is to be hoped that as our understanding of the complex relationships between stress, depression, and neuroplasticity grows, the functional interrelationship of one to another will become more clear. Even at this early point, the extensive mechanistic parallels between these disparate phenomena suggest a deep causal connection.

\section{SUMMARY AND CONCLUSIONS}

The molecular mechanisms of antidepressant response overlap with those of neuroplasticity to a striking degree. We have described three levels of neuroplasticity in which this parallel can be seen. Synaptic plasticity (including morphological change in dendritic spines and other concomitants of synaptic connections) has been well characterized in many brain regions, most prominently the hippocampus. Many of the molecular mechanisms of synaptic plasticity are induced by antidepressants; again, the hippocampus presents the best-characterized example of this fact. Parallels are seen both with the mechanisms of short-term plasticity - such as the insertion of AMPA receptors into the membrane and the modulation of CaMKII - and with those of long-term plasticity - such as the activation of transcription factors such as CREB and the induction of plasticity-enhancing genes such as BDNF.

Parallels are also seen at the level of dendritic morphology. Increases in dendritic branching can be induced by enriched environments (van Praag et al, 2000), growth factors, and other neuroplasticity-inducing manipulations. Similar increases in dendritic length and complexity can be induced by antidepressant treatment. Finally, neurogenesis represents a more recently appreciated but profound mechanism of neuroplasticity, permitting the insertion of new neurons into the dentate gyrus of the adult animal. Here, too, neurogenesis is stimulated both by plasticity-inducing stimuli (such as environmental enrichment, exercise, and electrical stimulation) and by antidepressant treatments. 
While it is difficult to examine these mechanisms in tissue from depressed humans, evidence exists for impairment of neuroplasticity in major depression. Molecular concomitants of certain aspects of synaptic plasticity - such as expression and phosphorylation of the transcription factor CREB - are reduced in post-mortem tissue from depressed subjects. Depression leads to shortening and reduced complexity of dendritic trees, in the hippocampus and the PFC. It remains to be determined whether neurogenesis is reduced in patients with major depression (the one study published to date was negative; Reif et al, 2006); but neurogenesis has been shown to occur in the human hippocampus in adulthood (Eriksson et al, 1998), and thorough examination of whether it is reduced in major depression is certainly warranted by the strength of the preclinical evidence.

Stress is well established to contribute to the development of major depression in susceptible individuals. It is likely that any comprehensive account of the pathophysiology of mood disorders will include an important causal role for psychological and physiological stress. It is therefore striking that chronic stress, too, opposes many forms of neuroplasticity. As reviewed above, chronic stress reduces synaptic plasticity and dendritic spines, reduces the length and complexity of dendrites, and impairs neurogenesis.

The convergence of these literatures - neuroplasticity, antidepressant response, and the consequences of chronic stress - on an overlapping set of molecular and cellular mechanisms is increasingly apparent and suggests a deep connection between these three phenomena. Further explorations and better understanding of these relationships is likely to point the way toward a deeper understanding of affective disorders and, it is to be hoped, toward novel treatments. This will include the development and use of novel strategies for imaging structural and molecular pathways in human subjects in vivo, as well as post-mortem and genetic studies to identify and define the exact alterations underlying the disruption of neuroplasticity in depressed subjects. The findings demonstrating altered neuroplasticity have already provided novel targets for drug development and future studies will continue to identify and refine the information for further development of more effective therapeutic interventions.

\section{DISCLOSURE/CONFLICT OF INTEREST}

RSD is a consultant for Taisho Pharmaceuticals and Psychogenics, has received funding for investigator initiated research from Lilly, Organon, Pfizer, Sepracor, and Roche, and has received speaker honorariums from Lilly, Pfizer, Sepracor, Roche, Bristol-Myers-Squibb and Wyeth-Ayerst. $\mathrm{CP}$ has no disclosures or conflicts to report.

\section{REFERENCES}

Abel T, Martin KC, Bartsch D, Kandel ER (1998). Memory suppressor genes: inhibitory constraints on the storage of long-term memory. Science 279: 338-341.

Abel T, Nguyen PV, Barad M, Deuel TA, Kandel ER, Bourtchouladze R (1997). Genetic demonstration of a role for PKA in the late phase of LTP in hippocampus-based long-term memory. Cell 88: 615-626.
Abercrombie HC, Schaefer SM, Larson CL, Oakes TR, Lindgren KA, Holden JE et al (1998). Metabolic rate in the right amygdala predicts negative affect in depressed patients. Neuroreport 9: 3301-3307.

Ahmed T, Frey JU, Korz V (2006). Long-term effects of brief acute stress on cellular signaling and hippocampal LTP. J Neurosci 26: 3951-3958.

Albo F, Pieri M, Zona C (2004). Modulation of AMPA receptors in spinal motor neurons by the neuroprotective agent riluzole. $J$ Neurosci Res 78: 200-207.

Alfonso J, Aguero F, Sanchez DO, Flugge G, Fuchs E, Frasch AC et al (2004). Gene expression analysis in the hippocampal formation of tree shrews chronically treated with cortisol. $J$ Neurosci Res 78: 702-710.

Alfonso J, Frick LR, Silberman DM, Palumbo ML, Genaro AM, Frasch AC (2006). Regulation of hippocampal gene expression is conserved in two species subjected to different stressors and antidepressant treatments. Biol Psych 59: 244-251.

Allain H, Lieury A, Brunet-Bourgin F, Mirabaud C, Trebon P, Le $\mathrm{Coz} F$ et al (1992). Antidepressants and cognition: comparative effects of moclobemide, viloxazine and maprotiline. Psychopharmacology (Berl) 106: S56-S61.

Alonso G (2000). Prolonged corticosterone treatment of adult rats inhibits the proliferation of oligodendrocyte progenitors present throughout white and gray matter regions of the brain. Glia 31: 219-231.

Altman J, Das GD (1965). Autoradiographic and histological evidence of postnatal hippocampal neurogenesis in rats. J Comp Neurol 124: 319-335.

American Psychiatric Association (2000). Diagnostic and Statistical Manual of Mental Disorders (DSM) IV-TR. American Psychiatric Press: Washington, DC.

Atkins CM, Selcher JC, Petraitis JJ, Trzaskos JM, Sweatt JD (1998). The MAP cascade is required for mammalian associative learning. Nat Neurosci 1: 602-609.

Autry AE, Grillo CA, Piroli GG, Rothstein JD, McEwen BS, Reagan LP (2006). Glucocorticoid regulation of GLT-1 glutamate transporter isoform expression in the rat hippocampus. Neuroendocrinology 83: 371-379.

Bagley J, Moghaddam B (1997). Temporal dynamics of glutamate efflux in the prefrontal cortex and in the hippocampus following repeated stress: effects of pretreatment with saline or diazepam. Neuroscience 77: 65-73.

Banasr M, Valentine GW, Li XY, Gourley S, Taylor J, Duman RS (2007). Chronic stress decreases cell proliferation in adult cerebral cortex of rat: reversal by antidepressant treatment. Biol Psych 62: 496-504.

Barad M, Bourtchouladze R, Winder DG, Golan H, Kandel ER (1998). Rolipram, a type IV-specific phosphodiesterase inhibitor, facilitates the establishment of long-lasting long-term potentiation and improves memory. Proc Natl Acad Sci USA 95: 1502015025.

Barbiero VS, Giambelli R, Musazzi L, Tiraboschi E, Tardito D, Perez J et al (2007). Chronic antidepressants induce redistribution and differential activation of alpha CaM Kinase II between presynaptic compartments. Neuropsychopharmacology; epub ahead of print.

Bartoletti A, Cancedda L, Reid SW, Tessarollo L, Porciatti V, Pizzorusso $\mathrm{T}$ et al (2002). Heterozygous knock-out mice for brain-derived neurotrophic factor show a pathway-specific impairment of long-term potentiation but normal critical period for monocular deprivation. J Neurosci 22: 10072-10077.

Bartsch D, Casadio A, Karl KA, Serodio P, Kandel ER (1998). CREB1 encodes a nuclear activator, a repressor, and a cytoplasmic modulator that form a regulatory unit critical for long-term facilitation. Cell 95: 211-223.

Baxter Jr LR, Schwartz JM, Phelps ME, Mazziotta JC, Guze BH, Selin CE et al (1989). Reduction of prefrontal cortex glucose 
metabolism common to three types of depression. Arch Gen Psych 46: 243-250.

Berman RM, Cappiello A, Anand A, Oren DA, Heninger GR, Charney DS et al (2000). Antidepressant effects of ketamine in depressed patients. Biol Psych 47: 351-354.

Berton O, McClung CA, Dileone RJ, Krishnan V, Renthal W, Russo SJ et al (2006). Essential role of BDNF in the mesolimbic dopamine pathway in social defeat stress. Science 311: 868-878.

Bito H, Deisseroth K, Tsien RW (1996). CREB phosphorylation and dephosphorylation: a $\mathrm{Ca}^{2+}$ and stimulus duration-dependent switch for hippocampal gene expression. Cell 87: 1203-1214.

Bleakman D, Alt A, Witkin JM (2007). AMPA receptors in the therapeutic management of depression. CNS Neurol Disord-Drug Targets 6: 117-126.

Blendy JA (2006). The role of CREB in depression and antidepressant treatment. Biol Psych 59: 1144-1150.

Bodnoff S, Humphreys A, Lehman J, Diamond D, Rose G, Meaney M (1995). Enduring effects of chronic corticosterone treatment on spatial learning, synaptic plasticity and hippocampal neuropathology in young and mid-aged rats. J Neurosci 15: 61-69.

Bonanno G, Giambelli R, Raiteri L, Tiraboschi E, Zappettini S, Muszzi L et al (2005). Chronic antidepressants reduce depolarization-evoked glutamate release and protein interactions favoring formation of SNARE complex in hippocampus. J Neurosci 25: 3270-3279.

Bremner JD, Narayan M, Anderson ER, Staib LH, Miller HL, Charney DS (2000). Hippocampal volume reductions in major depression. Am J Psych 157: 115-117.

Bukalo O, Fentrop N, Lee AY, Salmen B, Law JW, Wojak CT et al (2004). Conditional ablation of the neural cell adhesion molecule reduces precision of spatial learning, long-term potentiation, and depression in the CA1 subfield of the mouse hippocampus. J Neurosci 24: 1565-1577.

Cao L, Jiao X, Zuzga DS, Liu Y, Fong DM, Young D et al (2004). VEGF links hippocampal activity with neurogenesis, learning and memory. Nat Genet 36: 827-835.

Carlezon Jr WA, Duman RS, Nestler EJ (2005). The many faces of CREB. Trends Neurosci 28: 436-445.

Caspi A, Sugden K, Moffitt TE, Taylor A, Craig IW, Harrington H et al (2003). Influence of life stress on depression: moderation by a polymorphism in the 5-HTT gene. Science 301: 386-389.

Celano E, Tiraboschi E, Consogno E, D'Irso G, Mbakop MP, Gennarelli $M$ et al (2003). Selective regulation of presynaptic calcium/calmodulin-dependent protein kinase II by psychotropic drugs. Biol Psych 53: 442-449.

Chambers RA, Potenza MN, Hoffman RE, Miranker W (2004). Simulated apoptosis/neurogenesis regulates learning and memory capabilities of adaptive neural networks. Neuropsychopharmacology 29: 747-758.

Chen AC, Shirayama Y, Shin KH, Neve RL, Duman RS (2001a). Expression of the cAMP response element binding protein (CREB) in hippocampus produces an antidepressant effect. Biol Psych 49: 753-762.

Chen B, Dowlatshahi D, MacQueen GM, Wang JF, Young LT (2001b). Increased hippocampal BDNF immunoreactivity in subjects treated with antidepressant medication. Biol Psych 50: 260-265.

Chen ZY, Jing D, Bath KG, Ieraci A, Khan T, Siao CJ et al (2006). Genetic variant BDNF (Val66Met) polymorphism alters anxietyrelated behavior. Science 314: 140-143.

Conrad CD, Galea LA, Kuroda Y, McEwen BS (1996). Chronic stress impairs rat spatial memory on the Y maze, and this effect is blocked by tianeptine pretreatment. Behav Neurosci 110: 1321-1334.

Conrad CD, LeDoux JE, Magannos AM, McEwen BS (1999). Repeated restraint stress facilitates fear conditioning independently of causing hippocampal CA3 dendritic atrophy. Behav Neurosci 113: 902-913.
Conti AC, Cryan JF, Dalvi A, Lucki I, Blendy JA (2002). cAMP response element-binding protein is essential for the upregulation of brain-derived neurotrophic factor transcription, but not the behavioral or endocrine responses to antidepressant drugs. J Neurosci 22: 3262-3268.

Cook SC, Wellman CL (2004). Chronic stress alters dendritic morphology in rat medial prefrontal cortex. J Neurobiol 60: 236-248.

Cotter D, Mackay D, Chana G, Beasley C, Landau S, Everall IP (2002). Reduced neuronal size and glial cell density in area 9 of the dorsolateral prefrontal cortex in subjects with major depressive disorder. Cereb Cortex 12: 386-394.

Cotter D, Mackay D, Landau S, Kerwin R, Everall I (2001). Reduced glial cell density and neuronal size in the anterior cingulate cortex in major depressive disorder. Arch Gen Psych 58: 545-553.

De Kloet ER (2004). Hormones and the stressed brain. Ann NY Acad Sci 1018: 1-15.

De Quervain D, Roozendaal B, McGaugh J (1998). Stress and glucocorticoids impair retrieval of long-term spatial memory. Nature 394: 787-790.

De Quervain D, Roozendaal B, Nitsch R, McGaugh J, Hock C (2000). Acute cortisone administration impairs retrieval of longterm declarative memory in humans. Nat Neurosci 3: 313-317.

Deisseroth K, Singla S, Toda H, Monje M, Palmer TD, Malenka Rc (2004). Excitation-neurogenesis coupling in adult neural stem/progenitor cells. Neuron 42: 535-552.

Di Cristo G, Berardi N, Cancedda L, Pizzorusso T, Putingnano E, Ratto GM et al (2001). Requirement of ERK activation for visual cortical plasticity. Science 292: 2337-2340.

Diamond D, Park C, Heman K, Rose G (1999). Exposing rats to a predator impairs spatial working memory in the radial arm water maze. Hippocampus 9: 542-552.

Donati RJ, Rasenick MM (2003). G protein signaling and the molecular basis of antidepressant action. Life Sci 73: 1-17.

Dowlatshahi D, MacQueen GM, Wang JF, Young LT (1998). Increased temporal cortex CREB concentrations and antidepressant treatment in major depression. Lancet 352: 1754-1755.

Dranovsky A, Hen R (2006). Hippocampal neurogenesis: regulation by stress and antidepressants. Biol Psych 59: 1136-1143.

Drapeau E, Mayo W, Aurousseau C, Le Moal M, Piazza P, Abrous DN (2003). Spatial memory performances of aged rats in the water maze predict levels of hippocampal neurogenesis. Proc Natl Acad Sci USA 100: 14385-14390.

Drevets WC, Videen TO, Price JL, Preskorn SH, Carmichael ST, Raichle ME (1992). A functional anatomical study of unipolar depression. J Neurosci 12: 3628-3641.

Drevets WC (2003). Neuroimaging abnormalities in the amygdala in mood disorders. Ann NY Acad Sci 985: 420-444.

Du J, Suzuki K, Wei Y, Wang Y, Blumenthal R, Chen Z et al (2007). The anticonvulsants lamotrigine, riluzole, and valproate differentially regulate AMPA receptor membrane localization: relationship to clinical effects in mood disorders. Neuropsychopharmacology 32: 793-802.

Duman CH, Schlesinger L, Kodama M, Russell DS, Duman RS (2007). A role for MAPK signaling in behavioral models of depression and antidepressant treatment. Biol Psych 61: 661-670.

Duman RS, Heninger GR, Nestler EJ (1997). A molecular and cellular theory of depression. Arch Gen Psych 54: 597-606.

Duman RS, Monteggia LM (2006). A neurotrophic model for stress-related mood disorders. Biol Psych 59: 1116-1127.

Duman RS (2004). Depression: a case of neuronal life and death? Biol Psych 56: 140-145.

Dunn RT, Kimbrell TA, Ketter TA, Frye MA, Willis MW, Luckenbaugh DA et al (2002). Principal components of the Beck Depression Inventory and regional cerebral metabolism in unipolar and bipolar depression. Biol Psych 51: 387-399.

Dwivedi Y, Rizavi HS, Roberts RC, Conley RC, Tamminga CA, Pandey GN (2001). Reduced activation and expression of ERK 
1/2 MAP kinase in the post-mortem brain of depressed suicide subjects. J Neurochem 77: 916-928.

Dwivedi Y, Rao JS, Rizavi HS, Kotowski J, Conley RR, Roberts RC et al (2003). Abnormal expression and functional characteristics of cyclic adenosine monophosphate response element binding protein in postmortem brain of suicide subjects. Arch Gen Psych 60: $273-282$.

Dwivedi Y, Rizavi HS, Conley RR, Pandey GN (2006). ERK MAP kinase signaling in post-mortem brain of suicide subjects: differential regulation of upstream Raf kinases Raf- 1 and B-Raf. Mol Psych 11: 86-98.

Dwivedi Y, Rizavi HS, Teppen T, Sasaki N, Chen H, Zhang H et al (2007). Aberrant extracellular signal-regulated kinase (ERK) 5 signaling in hippocampus of suicide subjects. Neuropsychopharmacology; epub ahead of print.

Egan MF, Kojima M, Callicot JH, Goldberg TE, Kolachana BS, Bertolino A et al (2003). The BDNF val66met polymorphism affects activity-dependent secretion of BDNF and human memory and hippocampal function. Cell 112: 257-269.

Einat H, Yuan P, Gould TD, Li J, Du J, Zhang L et al (2003). The role of the extracellular signal-regulated kinase signaling pathway in mood modulation. J Neurosci 23: 7311-7316.

Eisch AJ, Bolanos CA, de Wit J, Simonak RD, Pudiak CM, Barrot M et al (2003). Brain-derived neurotrophic factor in the ventral midbrain-nucleus accumbens pathway: a role in depression. Biol Psych 54: 994-1005.

Engert F, Bonhoeffer T (1999). Dendritic spine changes associated with hippocampal long-term synaptic plasticity. Nature 399: 66-70.

Epstein J, Pan H, Kocsis JH, Yang Y, Butler T, Chusid J et al (2006). Lack of ventral striatal response to positive stimuli in depressed versus normal subjects. Am J Psych 163: 1784-1790.

Eriksson PS, Perfilieva E, Björk-Eriksson T, Alborm AM, Nordborg C, Peterson DA et al (1998). Neurogenesis in the adult human hippocampus. Nat Med 4: 1313-1317.

Focking M, Holker I, Trapp T (2003). Chronic glucocorticoid receptor activation impairs CREB transcriptional activity in clonal neurons. Biochem Biophys Res Comm 304: 720-723.

Foy MR, Stanton ME, Levine S, Thompson RF (1987). Behavioral stress impairs long-term potentiation in rodent hippocampus. Behav Neural Biol 48: 138-149.

Franklin TB, Perrot-Sinal TS (2006). Sex and ovarian steroids modulate brain-derived neurotrophic factor (BDNF) protein levels in rat hippocampus under stressful and non-stressful conditions. Psychoneuroendocrinology 31: 38-48.

Frechilla D, Otano A, del Río J (1998). Effect of chronic antidepressant treatment on transcription factor binding activity in rat hippocampus and frontal cortex. Prog Neuropsychopharm Biol Psych 22: 787-802.

Frodl T, Meisensahl E, Zetzsche T, Bottlender R, Born C, Groll C et al (2002). Enlargement of the amygdala in patients with first episode of major depression. Biol Psych 51: 708-714.

Fumagalli F, Frasca A, Sparta M, Drago F, Racagni G, Riva MA (2006). Long-term exposure to the atypical antipsychotic olanzapine differently up-regulates extracellular signal-regulated kinases 1 and 2 phosphorylation in subcellular compartments of rat prefrontal cortex. Mol Pharm 69: 1366-1372.

Fumagalli F, Molteni R, Calabrese F, Frasca A, Racagni G, Riva MA (2005). Chronic fluoxetine administration inhibits extracellular signal-related kinase $1 / 2$ phosphorylation in rat brain. J Neurochem 93: 1551-1560.

Gallassi R, Di Sarro R, Morreale A, Amore M (2006). Memory impairment in patients with late-onset major depression: the effect of antidepressant therapy. J Affect Disord 91: 243-250.

Giovannini MG (2006). The role of the extracellular signalregulated kinase pathway in memory encoding. Rev Neurosci 17: 619-634.

Glazewski S, Barth AL, Wallace H, McKenna M, Silva A, Fox K (1999). Impaired experience-dependent plasticity in barrel cortex of mice lacking the alpha and delta isoforms of CREB. Cereb Cortex 9: 249-256.

Goldman-Rakic PS (1996). Regional and cellular fractionation of working memory. Proc Natl Acad Sci USA 93: 13473-13480.

Gould E, Cameron HA, Daniels DC, Wooley CS, McEwen BS (1992). Adrenal hormones suppress cell division in the adult rat dentate gyrus. J Neurosci 12: 3642-3650.

Gould E, Cameron HA (1997). Early NMDA receptor blockade impairs defensive behavior and increases cell proliferation in the dentate gyrus of developing rats. Behav Neurosci 11: 49-56.

Grønli J, Bramham C, Murison R, Kanhema T, Fiske E, Bjorvatn B et al (2006). Chronic mild stress inhibits BDNF protein expression and CREB activation in the dentate gyrus but not in the hippocampus proper. Pharmacol Biochem Behav 85: 842-849.

Hajszan T, MacLusky NJ, Leranth C (2005). Short-term treatment with the antidepressant fluxoetine triggers pyramidal dendritic spine synapse formation in rat hippocampus. Eur J Neurosci 21: 1299-1303.

Hardingham GE, Bading $\mathrm{H}$ (2003). The yin and yang of NMDA receptor signaling. Trends Neurosci 26: 81-89.

Hardingham GE, Fukunaga Y, Bading H (2002). Extrasynaptic NMDARs oppose synaptic NMDRs by triggering CREB shut-off and cell death pathways. Nat Neurosci 5: 405-414.

Harvey PO, Fossati P, Pochon JB, Levy R, LeBastard G, Lehéricy S et al (2005). Cognitive control and brain resources in major depression: an fMRI study using the $n$-back task. Neuroimage 26: 860-869.

Hasler G, Drevets WC, Manji HK, Charney DS (2004). Discovering endophenotypes for major depression. Neuropsychopharmacology 29: 1765-1781.

Hebb DO (1949). The Organization of Behavior: A Neuropsychological Theory. Wiley: New York.

Heine VM, Zareno J, Maslam S, Joels M, Lucassen PJ (2005). Chronic stress in the adult dentate gyrus reduces cell proliferation near the vasculature and VEGF and Flk-1 protein expression. Eur J Neurosci 21: 1304-1314.

Heldt SA, Stanek L, Chhatwal JP, Ressler KJ (2007). Hippocampusspecific deletion of BDNF in adult mice impairs spatial memory and extinction of aversive memories. Mol Psych 12: 656-670.

Heninger GR, Delgado PL, Charney DS (1996). The revised monoamine theory of depression: a modulatory role for monoamines, based on new findings from monoamine depletion experiments in humans. Pharmacopsychiatry 29: 2-11.

Holderbach R, Clark K, Moreau JL, Bischofberger J, Normann C (2007). Enhanced long-term synaptic depression in an animal model of depression. Biol Psych 62: 92-100.

Hoshaw BA, Malberg JE, Lucki I (2005). Central administration of IGF-I and BDNF leads to long-lasting antidepressant effects. Brain Res 1037: 204-208.

Huang YY, Martin KC, Kandel ER (2000). Both protein kinase A and mitogen-activated protein kinase are required in the amygdala for the macromolecular synthesis-dependent late phase of long-term potentiation. J Neurosci 20: 6317-6325.

Jaffard R, Mocaer E, Poignant JC, Micheau J, Marighetto A, Meunier $M$ et al (1991). Effects of tianeptine on spontaneous alternation, simple and concurrent spatial discrimination learning and on alcohol-induced alternation deficits in mice. Behav Pharm 2: 37-46.

Kandel ER (2001). The molecular biology of memory storage: a dialogue between genes and synapses. Science 294: 1030-1038.

Kang H, Sun LD, Atkins CM, Soderling TR, Wilson MA, Tonegawa $S$ (2001). An important role of neural activity-dependent CaMKIV signaling in the consolidation of long-term memory. Neuron 106: 771-783.

Kaplan MS, Hinds JW (1977). Neurogenesis in the adult rat: electron microscopic analysis of light radioautographs. Science 197: $1092-1094$ 
Karege F, Perret G, Bondolfi G, Schwald M, Bertschy G, Aubry JM (2002). Decreased serum brain-derived neurotrophic factor levels in major depressed patients. Psych Res 109: 143-148.

Karege F, Vaudan G, Schwald M, Perroud N, La Harpe R (2005). Neurotrophin levels in postmortem brains of suicide victims and the effects of antemortem diagnosis and psychotropic drugs. Brain Res Mol Brain Res 136: 29-37.

Karst H, Joëls M (2005). Corticosterone slowly enhances miniature excitatory postsynaptic current amplitude in mice CA1 hippocampal cells. J Neurophys 94: 3479-3485.

Kasselman LJ, Kintner J, Sideris A, Pasnikowski E, Krellman JW, Shah S et al (2007). Dexamethasome treatment and ICAM-1 deficiency impair VEGF-induced angiogenesis in adult brain. J Vasc Res 44: 283-291.

Kaufman J, Yang BZ, Douglas-Palumberi H, Grasso D, Lipschtz D, Houshyar S et al (2006). Brain-derived neurotrophic factor5-HTTLPR gene interactions and environmental modifiers of depression in children. Biol Psych 59: 673-680.

Kempermann G, Kuhn HG, Gage FH (1997). More hippocampal neurons in adult mice living in an enriched environment. Nature 386: 493-495.

Kendler KS, Karkowski LM, Prescott CA (1999). Causal relationship between stressful life events and the onset of major depression. Am J Psych 156: 837-841.

Kida S, Josselyn SA, de Ortiz SP, Kogan JH, Chevere I, Masushige S et al (2002). CREB required for the stability of new and reactivated fear memories. Nat Neurosci 5: 348-355.

Kim JJ, Diamond DM (2002). The stressed hippocampus, synaptic plasticity and lost memories. Nature Rev Neurosci 3: 453-462.

Kim JJ, Foy MR, Thompson RF (1996). Behavioral stress modifies hippocampal plasticity through $N$-methyl-aspartate receptor activation. Proc Natl Acad Sci USA 93: 4750-4753.

Koch JM, Kell S, Hinze-Selch D, Aldenhoff JB (2002). Changes in CREB-phosphorylation during recovery from major depression. J Psych Res 36: 369-375.

Lange C, Irle E (2004). Enlarged amygdala volume and reduced hippocampal volume in young women with major depression. Psychol Med 34: 1059-1064.

Lee SY, Kang JS, Song GY, Myung CS (2006). Stress induces the expression of heterotrimeric $G$ protein beta subunits and the phosphorylation of $\mathrm{PKB} / \mathrm{Akt}$ and ERK1/2 in rat brain. Neurosci Res 56: 180-192.

Leuner B, Gould E, Shors TJ (2006). Is there a link between adult neurogenesis and learning? Hippocampus 16: 216-224.

Levkovitz Y, Grisaru N, Segal N (2001). Transcranial magnetic stimulation and antidepressive drugs share similar cellular effects in rat hippocampus. Neuropsychopharmacology 24: 608-616.

Luine V, Martinez C, Villegas M, Magarinos A, McEwen B (1996). Restraint stress reversibly enhances spatial memory performance. Physiol Behav 59: 27-32.

Lisman JE, Goldring MA (1988). Feasibility of long-term storage of graded information by the $\mathrm{Ca}^{2+} /$ calmodulin-dependent protein kinase molecules of the postsynaptic density. Proc Natl Acad Sci USA 85: 5320-5324.

Lisman JE, Grace AA (2005). The hippocampal-VTA loop: controlling the entry of information into long-term memory. Neuron 46: 703-713.

Liston C, Miller M, Goldwater DS, Radley JJ, Rocher AB, Hof PR et al (2006). Stress-induced alterations in prefrontal cortical dendritic morphology predict selective impairments in perceptual attentional set-shifting. J Neurosci 26: 7870-7874.

Lowy MT, Gault L, Yamamoto BK (1993). Adrenalectomy attenuates stress-induced elevations in extracellular glutamate concentrations in the hippocampus. J Neurochem 61: 1957-1960.

MacQueen GM, Campbell S, McEwen BS, Macdonald K, Amano S, Joffe RT et al (2003). Course of illness, hippocampal function, and hippocampal volume in major depression. Proc Natl Acad Sci USA 100: 1387-1392.

Magariños AM, Deslandes A, McEwen BS (1999). Effects of antidepressants and benzodiazepine treatments on the dendritic structure of CA3 pyramidal neurons after chronic stress. Eur J Pharmacol 371: 113-122.

Magarinos AM, McEwen BS, Flugge G, Fuchs E (1996). Chronic psychosocial stress causes apical dendritic atrophy of hippocampal CA3 pyramidal neurons in subordinate tree shrews. J Neurosci 16: 3534-3540.

Magariños AM, McEwen BS (1995). Stress-induced atrophy of apical dendrites of hippocampal CA3c neurons: involvement of glucocorticoid secretion and excitatory amino acid receptors. Neuroscience 69: 89-98.

Malberg JE, Eisch AJ, Nestler EJ, Duman RS (2000). Chronic antidepressant treatment increases neurogenesis in adult rat hippocampus. J Neurosci 20: 9104-9110.

Malenka RC, Bear MF (2004). LTP and LTD: an embarrassment of riches. Neuron 44: 5-21.

Malenka RC, Nicoll RA (1997). Silent synapses speak up. Neuron 19: 473-476.

Malleret G, Haditsch U, Genoux D, Jones MW, Bliss TV, Vanhoose $\mathrm{AM}$ et al (2001). Inducible and reversible enhancement of learning, memory, and long-term potentiation by genetic inhibition of calcineurin. Cell 104: 675-686.

Manji HK, Quiroz JA, Sporn J, Payne JL, Denicoff K, Gray NA et al (2003). Enhancing neuronal plasticity and cellular resilience to develop novel, improved therapeutics for difficult-to-treat depression. Biol Psych 53: 707-742.

Maroun M, Richter-Levin G (2003). Exposure to acute stress blocks the induction of long-term potentiation of the amygdala-prefrontal cortex pathway in vivo. J Neurosci 23: 4406-4409.

Maroun M (2006). Stress reverses plasticity in the pathway projecting from the ventromedial prefrontal cortex to the basolateral amygdala. Eur J Neurosci 24: 2917-2922.

Massicotte G, Bernard J, Ohayon M (1993). Chronic effects of trimipramine, an antidepressant, on hippocampal synaptic plasticity. Behav Neural Biol 59: 100-106.

Matsuzaki M, Honkura N, Ellis-Davies GC, Kasai H (2004). Structural basis of long-term potentiation in single dendritic spines. Nature 429: 761-766.

McEwen BS (1999). Stress and hippocampal plasticity. Ann Rev Neurosci 22: 105-122.

Metsis M, Timmusk T, Arenas E, Persson H (1993). Differential usage of multiple brain-derived neurotrophic factor promoters in the rat brain following neuronal activation. Proc Natl Acad Sci USA 90: 8802-8806.

Miller RG, Mitchell JD, Lyon M, Moore DH (2007). Riluzole for amyotrophic lateral sclerosis (ALS)/motor neuron disease (MND). Cochrane Database Syst Rev 1: CD00147 (Review).

Ming G, Song H (2005). Adult neurogenesis in the mammalian central nervous system. Ann Rev Neurosci 28: 223-250.

Moghaddam B, Adams B, Verma A, Daly D (1997). Activation of glutamatergic neurotransmission by ketamine: a novel step in the pathway from NMDA receptor blockade to dopaminergic and cognitive disruptions associated with the prefrontal cortex. J Neurosci 17: 2921-2927.

Monteggia LM, Barrot M, Powell CM, Berton O, Galanis V, Gemelli $\mathrm{T}$ et al (2004). Essential role of brain-derived neurotrophic factor in adult hippocampal function. Proc Natl Acad Sci USA 101: 10827-10832.

Monteggia LM, Luikart B, Barrot M, Theobold D, Malkovska I, Nef $S$ et al (2007). Brain-derived neurotrophic factor conditional knockouts show gender differences in depression-related behaviors. Biol Psych 61: 187-197.

Mowla A, Mosavinasab M, Pani A (2007). Does fluoxetine have any effects on the cognition of patients with mild cognitive 
impairment? A double-blind, placebo-controlled, clinical trial. J Clin Psychopharm 27: 67-70.

Muller D, Wang C, Skibo G, Toni N, Cremer H, Calaora V et al (1996). PSA-NCAM is required for activity-induced synaptic plasticity. Neuron 17: 413-422.

Nair A, Vadodaria KC, Banerjee SB, Benekareddy M, Dias BG, Duman RS et al (2007). Stressor-specific regulation of distinct brain-derived neurotrophic factor transcripts and cyclic AMP response element-binding protein expression in the postnatal and adult rat hippocampus. Neuropsychopharmacology 32: 1504-1519.

Nakagawa S, Kim JE, Lee R, Malberg JE, Chen J, Steffen C et al (2002a). Regulation of neurogenesis in adult mouse hippocampus by cAMP and the cAMP response element-binding protein. J Neurosci 22: 3673-3682.

Nakagawa S, Kim JE, Lee R, Chen J, Fujioka T, Malberg J et al (2002b). Localization of phosphorylated cAMP response element-binding protein in immature neurons of adult hippocampus. J Neurosci 22: 9868-9876.

Naudon L, Hotte M, Jay TM (2007). Effects of acute and chronic antidepressant treatment on memory performance: a comparison between paroxetine and imipramine. Psychopharmacology (Berl) 191: 353-364.

Nemeroff CB (2006). Use of atypical antipsychotics in refractory depression and anxiety. J Clin Psych 66(S8): 13-21.

Nestler EJ, Carlezon Jr WA (2006). The mesolimbic dopamine reward circuit in depression. Biol Psych 59: 1151-1159.

Nestler EJ, Terwilliger RZ, Duman RS (1989). Chronic antidepressant administration alters the subcellular distribution of cyclic AMP-dependent protein kinase in rat frontal cortex. $J$ Neurochem 53: 1655-1657.

Newcomer J, Selke G, Melson A, Hershey T, Craft S, Richards K et al (1999). Decreased memory performance in healthy humans induced by stress-level cortisol treatment. Arch Gen Psych 56: 527-533.

Newton SS, Colier EF, Hunsberger J, Adams D, Terwilliger R, Selvanayagam E et al (2003). Gene profile of electroconvulsive seizures: induction of neurotrophic and angiogenic factors. J Neurosci 23: 10841-10851.

Newton SS, Duman RS (2004). Regulation of neurogenesis and angiogenesis in depression. Curr Neurovasc Res 1: 261-267.

Newton SS, Thome J, Wallace TL, Shirayama Y, Schlesinger L, Sakai $\mathrm{N}$ et al (2002). Inhibition of cAMP response element-binding protein or dynorphin in the nucleus accumbens produces an antidepressant-like effect. J Neurosci 22: 10883-10890.

Nguyen PV, Abel T, Kandel ER (1994). Requirement of a critical period of transcription for induction of a late phase of LTP. Science 265: 1104-1107.

Nibuya M, Morinobu S, Duman RS (1995). Regulation of BDNF and TrkB mRNA in rat brain by chronic electroconvulsive seizure and antidepressant drug treatments. J Neuosci 15: 7539-7547.

Nibuya M, Nestler EJ, Duman RS (1996). Chronic antidepressant administration increases the expression of cAMP response element binding protein (CREB) in rat hippocampus. $J$ Neurosci 16: $2365-2372$.

Nibuya M, Takahashi M, Russell DS, Duman RS (1999). Repeated stress increases catalytic TrkB mRNA in rat hippocampus. Neurosci Lett 267: 81-84.

Norrholm SD, Ouimet CC (2001). Altered dendritic spine density in animal models of depression and in response to antidepressant treatment. Synapse 42: 151-163.

Nowakowska E, Kus K, Chodera A, Rybakowski J (2000). Behavioural effects of fluoxetine and tianeptine, two antidepressants with opposite action mechanisms, in rats. Arzneimittelforschung 50: 5-10.

Nowakowska E, Kus K, Chodera A (2003). Comparison of behavioural effects of venlafaxine and imipramine in rats. Arzneimittelforschung 53: 237-242.
Nowakowska E, Kus K, Florek E, Czubak A, Jodynis-Liebert J (2006). The influence of tobacco smoke and nicotine on antidepressant and memory-improving effects of venlafaxine. Hum Exp Toxicol 25: 199-209.

O’Connor JJ, Rowan MJ, Anwyl R (1993). Naunyn Schmiedebergs Arch. Pharmacology 348: 158-163.

Odagaki Y, García-Sevilla JA, Huguelet P, La Harpe R, Koyama T, Gulmón J (2001). Cyclic AMP-mediated signaling components are upregulated in the prefrontal cortex of depressed suicide victims. Brain Res 898: 224-231.

O'Donnell JM, Zhang HT (2004). Antidepressant effects of inhibitors of cAMP phosphodiesterase (PDE4). Trends Pharm Sci 25: $158-163$.

Ongur D, Drevets WC, Price JL (1998). Glial reduction in the subgenual prefrontal cortex in mood disorders. Proc Natl Acad Sci USA 95: 13290-13295.

Ortiz J, Fitzgerald LW, Lane S, Terwilliger R, Nestler EJ (1996). Biochemical effects of repeated stress in the mesolimbic dopamine system. Neuropsychopharmacology 14: 393-402.

Pang PT, Lu B (2004). Regulation of late-phase LTP and long-term memory in normal and aging hippocampus: role of secreted proteins tPA and BDNF. Ageing Res Rev 3: 407-430.

Pardon MC, Roberts ME, Marsden CA, Bianchi M, Latif ML, Duxon MS et al (2005). Social threat and novel cage stress-induced sustained extracellular-regulated kinase 1/2 (ERK 1/2) phosphorylation but differential modulation of brain-derived neurotrophic factor (BDNF) expression in the hippocampus of NMRI mice. Neuroscience 132: 561-574.

Patterson SL, Abel T, Deuel TA, Martin KC, Rose JC, Kandel ER (1996). Recombinant BDNF rescues deficits in basal synaptic transmission and hippocampal LTP in BDNF knockout mice. Neuron 16: 1137-1145.

Patterson SL, Grover LM, Schwartzkroin PA, Bothwell M (1992). Neurotrophin expression in rat hippocampal slices: a stimulus paradigm inducing LTP in CA evokes increases in BDNF and NT-3 mRNAs. Neuron 9: 1081-1088.

Patterson SL, Pittenger C, Morozov A, Martin KC, Scanlin H, Drake $C$ et al (2001). Some forms of cAMP-mediated long-lasting potentiation are associated with release of BDNF and nuclear translocation of phospho-MAP kinase. Neuron 32: 123-140.

Paul IA, Skolnick P (2003). Glutamate and depression: clinical and preclinical studies. Ann NY Acad Sci 1003: 250-272.

Perez J, Tardito D, Mori S, Racagni G, Smeraldi E, Zanardi R (2000). Abnormalities of cAMP signaling in affective disorders: implication for pathophysiology and treatment. Bipolar Disord 2: 27-36.

Perez J, Tinelli D, Brunello N, Racagni G (1989). cAMP-dependent phosphorylation of soluble and crude microtubule fractions of rat cerebral cortex after prolonged desmethylimipramine treatment. Eur J Pharmacol 172: 305-316.

Perlis RH, Purcell S, Fagerness J, Cusin C, Yamaki L, Fava M et al (2007). Clinical and genetic dissection of anger expression and CREB1 polymorphisms in major depressive disorder. Biol Psych 62: $536-540$.

Pickering C, Gustafsson L, Cebere A, Nylander I, Liljequist S (2006). Repeated maternal separation of male Wistar rats alters glutamate receptor expression in the hippocampus but not the prefrontal cortex. Brain Res 1099: 101-108.

Pittenger C, Fasano S, Mazzocchi-Jones D, Dunnett SB, Kandel ER, Brambilla R (2006). Impaired bidirectional synaptic plasticity and procedural memory formation in striatum-specific cAMP response element-binding protein-deficient mice. J Neurosci 26: 2808-2813.

Pittenger C, Huang YY, Paletzki RF, Bourtchouladze R, Scanlin H, Vronskaya S; et al (2002). Reversible inhibition of CREB/ATF transcription factors in region CA1 of the dorsal hippocampus disrupts hippocampus-dependent spatial memory. Neuron 34: 447-462. 
Pittenger C, Sanacora G, Krystal JH (2007). The NMDA receptor as a therapeutic target in major depressive disorder. CNS Neurol Disord-Drug Targets 6: 101-115.

Pliakas AM, Carlson RR, Neve RL, Konradi C, Nestler EJ, Carlezon Jr WA (2001). Altered responsiveness to cocaine and increased immobility in the forced swim test associated with elevated cAMP response element-binding protein expression in nucleus accumbens. J Neurosci 21: 7397-7403.

Popoli M, Vocaturo C, Perez J, Smeraldi E, Racagni G (1995). Presynaptic $\mathrm{Ca}^{2+} /$ calmodulin-dependent protein kinase II: autophosphorylation and activity increase in the hippocampus after long-term blockade of serotonin reuptake. Mol Pharm 48: 623-629.

Radley JJ, Sisti HM, Hao J, Rocher AB, McCall T, Hof PR et al (2004). Chronic behavioral stress induces apical dendrite reorganization in pyramidal neurons of the medial prefrontal cortex. Neuroscience 125: 1-6.

Rajkowska G, Miguel-Hidalgo JJ, Wei J, Dilley G, Pittman SD, Meltzer HY et al (1999). Morphometric evidence for neuronal and glial prefrontal cell pathology in major depression. Biol Psych 45: 1085-1098.

Rajkowska G, O’Dwyer G, Teleki Z, Stockmeier CA, MiguelHidalgo JJ (2007). GABAergic neurons immunoreactive for calcium binding proteins are reduced in the prefrontal cortex in major depression. Neuropsychopharmacology 32: 471-482.

Rasmusson AM, Shi L, Duman R (2002). Downregulation of BDNF mRNA in the hippocampal dentate gyrus after re-exposure to cues previously associated with footshock. Neuropsychopharmacology 27: 133-142.

Rattiner LM, Davis M, Ressler KJ (2005). Brain-derived neurotrophic factor in amygdala-dependent learning. Neuroscientist 11: 323-333.

Reif A, Fritzen S, Finger M, Strobel A, Lauer M, Schmitt A et al (2006). Neural stem cell proliferation is decreased in schizophrenia, but not in depression. Mol Psych 11: 514-522.

Revest JM, Di Blasi F, Kitchener P, Rougé-Pont F, Desmedt A, Turiault $\mathrm{M}$ et al (2005). The MAPK pathway and Egr-1 mediate stress-related behavioral effects of glucocorticoids. Nat Neurosci 8: 664-672.

Reynolds IJ, Miller RJ (1988). Tricyclic antidepressants block $\mathrm{N}$-methyl-D-aspartate receptors: similarities to the action of zinc. Br J Pharmacol 95: 95-102.

Rocher C, Spedding M, Munoz C, Jay TM (2004). Acute stressinduced changes in hippocampal/prefrontal circuits in rats: effects of antidepressants. Cereb Cortex 14: 224-229.

Russo-Neustadt A, Ha T, Ramirez R, Kesslak JP (2001). Physical activity-antidepressant treatment combination: impact on brainderived neurotrophic factor and behavior in an animal model. Behav Brain Res 120: 87-95.

Saal D, Dong Y, Bonci A, Malenka RC (2003). Drugs of abuse and stress trigger a common synaptic adaptation in dopamine neurons. Neuron 37: 577-582.

Saarelainen T, Hendolin P, Lucas G, Koponen E, Sairanen M, MacDonald E et al (2003). Activation of the TrkB neurotrophin receptor is induced by antidepressant drugs and is required for antidepressant-induced behavioral effects. J Neurosci 23: 349-357.

Sackeim HA, Freeman J, McElhiney M, Coleman E, Prudic J, Devanand DP (1992). Effects of major depression on estimates of intelligence. J Clin Exp Neuropsychol 14: 268-288.

Sackeim HA (2000). Memory and ECT: from polarization to reconciliation. J ECT 16: 87-96.

Sairanen M, Lucas G, Ernfors P, Castren M, Casren E (2005). Brainderived neurotrophic factor and antidepressant drugs have different but coordinated effects on neuronal turnover, proliferation, and survival in the adult dentate gyrus. J Neurosci 25: 1089-1094.

Salm AK, Pavelko M, Krouse EM, Webster W, Kraszpulski M, Birkle DL (2004). Lateral amygdaloid nucleus expansion in adult rats is associated with exposure to prenatal stress. Brain Res Dev Brain Res 148: 159-167.

Sanacora G, Kendell SF, Levin Y, Simen AA, Fenton LR, Coric V et al (2007). Preliminary evidence of riluzole efficacy in antidepressant-treated patients with residual depressive symptoms. Biol Psych 61: 822-825.

Sanes JR, Lichtman JW (1999). Can molecules explain long-term potentiation? Nat Neurosci 2: 597-604.

Santarelli L, Saxe M, Gross C, Surget A, Battaglia F, Dulawa S et al (2003). Requirement of hippocampal neurogenesis for the behavioral effects of antidepressants. Science 301: 805-809.

Sapolsky RM (2003). Stress and plasticity in the limbic system. Neurochem Res 28: 1735-1742.

Sapolsky RM, Krey L, McEwen B (1985). Prolonged glucocorticoid exposure reduces hippocampal neuron number: implications for aging. J Neurosci 5: 1221-1227.

Sapolsky RM (2000). Glucocorticoids and hippocampal atrophy in neuropsychiatric disorders. Arch Gen Psych 57: 925-935.

Saxe MD, Battaglia F, Wang JW, Malleret G, David DJ, Monckton JE et al (2006). Ablation of hippocampal neurogenesis impairs contextual fear conditioning and synaptic plasticity in the dentate gyrus. Proc Natl Acad Sci USA 103: 17501-17506.

Schaaf MJ, de Kloet ER, Vreugdenhil E (2000). Corticosterone effects on BDNF expression in the hippocampus. Implications for memory formation. Stress 3: 201-208.

Schlaepfer TE, Cohen MX, Frick C, Kosel M, Brodesser D, Axmacher $\mathrm{N}$ et al (2007). Deep brain stimulation to reward circuitry alleviates anhedonia in refractory major depression. Neuropsychopharmacology; epub ahead of print.

Shah PJ, Ebmeier KP, Glabus MF, Goodwin GM (1998). Cortical grey matter reductions associated with treatment-resistant chronic unipolar depression. Controlled magnetic resonance imaging study. Br J Psych 172: 527-532.

Sheline YI, Sanghavi M, Mintun MA, Gado MH (1999). Depression duration but not age predicts hippocampal volume loss in medically healthy women with recurrent major depression. J Neurosci 19: 5034-5043.

Shimizu E, Hashimoto K, Okamura N, Koike K, Komatsu N, Kumakiri C et al (2003). Alterations of serum levels of brainderived neurotrophic factor (BDNF) in depressed patients with or without antidepressants. Biol Psych 54: 70-75.

Shirayama Y, Chen AC, Nakagaway S, Russell DS, Duman RS (2002). Brain-derived neurotrophic factor produces antidepressant effects in behavioral models of depression. J Neurosci 22: 3251-3261.

Shors TJ (2001). Acute stress rapidly and persistently enhances memory formation in the male rat. Neurobiol Learn Mem 75: $10-29$.

Shors TJ (2005). Stressful experience and learning across the lifespan. Ann Rev Psychol 57: 55-85.

Shors TJ, Miesegaes G, Beylin A, Zhao M, Rydel T, Gould E (2001). Neurogenesis in the adult is involved in the formation of trace memories. Nature 410: 372-376.

Shors TJ, Seib TB, Levine S, Thompson RF (1989). Inescapable versus escapable shock modulates long-term potentiation in the rat hippocampus. Science 244: 224-226.

Silva-Gomez AB, Rojas D, Juarez I, Flores G (2003). Decreased dendritic spine density on prefrontal cortical and hippocampal pyramidal neurons in postweaning social isolation rats. Brain Res 983: 128-136.

Siuciak JA, Lewis DR, Wiegand SJ, Lindsay RM (1997). Antidepressant-like effect of brain-derived neurotrophic factor (BDNF). Pharmacol Biochem Behav 56: 131-137.

Smith MA, Makino S, Kvetnansky R, Post RM (1995). Stress and glucocorticoids affect the expression of brain-derived neurotrophic factor and neurotrophin-3 mRNAs in the hippocampus. J Neurosci 15: 1768-1777. 
Snyder JS, Hong NS, McDonald RJ, Wojtowicz JM (2005). A role for adult neurogenesis in spatial long-term memory. Neuroscience 130: 843-852.

Squire LR, Stark CE, Clark RE (2004). The medial temporal lobe. Ann Rev Neurosci 27: 279-306.

Stewart CA, Reid IC (2000). Repeated ECS and fluoxetine administration have equivalent effects on hippocampal synaptic plasticity. Psychopharmacology (Berl) 148: 217-223.

Stockmeier CA, Mahajan GJ, Konick LC, Overholser JC, Jurjus GJ, Meltzer HY et al (2004). Cellular changes in the postmortem hippocampus in major depression. Biol Psych 56: 640-650.

Svenningsson P, Tzavara ET, Witkin JM, Fienberg AA, Nomikos GG, Greengard P (2002). Involvement of striatal and extrastriatal DARP-32 in biochemical effects of fluoxetine (Prozac). Proc Natl Acad Sci USA 99: 3182-3187.

Tardito D, Perez J, Tiraboschi E, Musazzi L, Racagni G, Popoli M (2006). Signaling pathways regulating gene expression, neuroplasticity, and neurotrophic mechanisms in the action of antidepressants: a critical overview. Pharmacol Rev 58: 115-134.

Tashiro A, Makino H, Gage FH (2007). Experience-specific functional modification of the dentate gyrus through adult neurogenesis: a critical period during an immature stage. J Neurosci 27: 3252-3259.

Thome J, Sakai N, Shin K, Steffen C, Zhang YJ, Impey S et al (2000). cAMP response element-mediated gene transcription is upregulated by chronic antidepressant treatment. J Neurosci 20: 4030-4036.

Tiraboschi E, Giambelli R, D’Urso G, Galietta A, Barbon A, de Bartolomeis A et al (2004a). Antidepressants activate CaMKII in neuron cell body by Thr286 phosphorylation. Neuroreport 15: 2393-2396.

Tiraboschi E, Tardito D, Kasahara J, Moraschi S, Pruneri P, Genarelli $\mathrm{M}$ et al (2004b). Selective phosphorylation of nuclear CREB by fluoxetine is linked to activation of CaMK IV and MAP kinase cascades. Neuropsychopharm 29: 1831-1840.

Toni N, Teng EM, Bushong EA, Aimone JB, Zhao C, Consiglio A et al (2007). Synapse formation on neurons born in the adult hippocampus. Nat Neurosci 10: 727-734.

Tononi G, Cirelli C (2006). Sleep function and synaptic homeostasis. Sleep Med Rev 10: 49-62.

Uranova NA, Vostrikov VM, Orlovskaya DD, Rachmanova VI (2004). Oligodendroglial density in the prefrontal cortex in schizophrenia and mood disorders: a study from the Stanley Neuropathology Consortium. Schizophr Res 67: 269-275.

Van Praag H, Kempermann G, Gage FH (2000). Neural consequences of environmental enrichment. Nat Rev Neurosci 1: 191-198.

Venero C, Borrell J (1999). Rapid glucocorticoid effects on excitatory amino acid levels in the hippocampus: a microdialysis study in freely moving rats. Eur J Neurosci 11: 2465-2473.

Vermetten E, Vythilingam M, Southwick SM, Charney DS, Bremner JD (2003). Long-term treatment with paroxetine increases verbal declarative memory and hippocampal volume in posttraumatic stress disorder. Biol Psychiatry 54: 693-702.

Von Frijtag JC, Kamal A, Reijmers LG, Schrama LH, van den Bos R, Spruijt BM (2001). Chronic imipramine treatment partially reverses the long-term changes of hippocampal synaptic plasticity in socially stressed rats. Neurosci Lett 309: 153-156.

Vouimba RM, Munoz C, Diamond DM (2006). Differential effects of predator stress and the antidepressant tianeptine on physiological plasticity in the hippocampus and basolateral amygdala. Stress 9: 29-40.

Vyas A, Bermal S, Chattarji S (2003). Effects of chronic stress on dendritic arborization in the central and extended amygdala. Brain Res 965: 290-294.

Vyas A, Jadhav S, Chattarji S (2006). Prolonged behavioral stress enhances synaptic connectivity in the basolateral amygdala. Neuroscience 143: 387-393.
Vyas A, Mitra R, Shankaranarayana Rao BS, Chattarji S (2002). Chronic stress induces contrasting patterns of dendritic remodeling in hippocampal and amygdaloid neurons. J Neurosci 22: 6810-6818.

Vyas A, Pillai AG, Chatarji S (2004). Recovery after chronic stress fails to reverse amygdaloid neuronal hypertrophy and enhanced anxiety-like behavior. Neuroscience 128: 667-673.

Vythilingam M, Vermetten E, Anderson GM, Luckenbaugh D, Anderson ER, Snow J et al (2004). Hippocampal volume, memory, and cortisol status in major depressive disorder: effects of treatment. Biol Psych 56: 101-112.

Warner-Schmidt JL, Duman RS (2006). Hippocampal neurogenesis: opposing effects of stress and antidepressant treatment. Hippocampus 16: 239-249.

Warner-Schmidt JL, Duman RS (2007). VEGF is an essential mediator of the neurogenic and behavioral actions of antidepressants. Proc Natl Acad Sci USA 104: 4647-4652.

Watanabe Y, Gould E, McEwen BS (1992). Stress induces atrophy of apical dendrites of hippocampal CA3 pyramidal neurons. Brain Res 588: 341-345.

Wellman CL (2001). Dendritic reorganization in pyramidal neurons in medial prefrontal cortex after chronic corticosterone administration. J Neurobiol 49: 245-253.

Willner P (2005). Chronic mild stress (CMS) revisited: consistency and behavioural-neurobiological concordance in the effects of CMS. Neuropsychobiology 52: 90-110.

Witkin JM, Marek GJ, Johnson BG, Schoepp DD (2007). Metabotropic glutamate receptors in the control of mood disorders. CNS Neurol Disord-Drug Targets 6: 87-100.

Woolley C, Gould E, McEwen B (1990). Exposure to excess glucocorticoids alters dendritic morphology of adult hippocampal pyramidal neurons. Brain Res 521: 225-231.

Xu L, Anwyl R, Rowan MJ (1997). Behavioural stress facilitates the induction of long-term depression in the hippocampus. Nature 387: 497-500.

Yamada S, Yamamoto M, Ozawa H, Riederer P, Saito T (2003). Reduced phosphorylation of cyclic AMP-responsive element binding protein in the postmortem oribitofrontal cortex of patients with major depressive disorder. J Neural Transm 110: 671-680.

Yang CH, Huang CC, Hsu KS (2004). Behavioral stress modifies hippocampal plasticity through corticosterone-induced sustained extracellular signal-regulate kinase/mitogen-activated protein kinase activation. J Neurosci 24: 11029-11034.

Yau JL, Noble J, Hibberd C, Rowe WB, Meaney MJ, Morris RG et al (2002). Chronic treatment with the antidepressant amitriptyline prevents impairments in water maze learning in aging rats. J Neurosci 22: 1436-1442.

Zakzanis KK, Leach L, Kaplan E (1998). On the nature and pattern of neurocognitive function in major depressive disorder. Neuropsych Neuropsychol Behav Neurol 11: 111-119.

Zarate Jr CA, Payne JL, Quiroz J, Sporn J, Denicoff KK, Luckenbaugh D et al (2004). An open-label trial of riluzole in patients with treatment-resistant major depression. Am J Psych 161: 171-174.

Zarate CA, Singh JB, Carlson PJ, Brutsche NE, Ameli R, Luckenbaugh DA et al (2006). A randomized trial of an $\mathrm{N}$-methyl-D-aspartate antagonist in treatment-resistant major depression. Arch Gen Psychiatry 63: 856-864.

Zschocke J, Bayatti N, Clement AM, Witan H, Figiel M, Engele $\mathrm{J}$ et al (2005). Differential promotion of glutamate transporter expression and function by glucocorticoids in astrocytes from various brain regions. J Biol Chem 280: 34924-34932.

Zubenko GS, Hughes III HB, Stiffler JS, Brechbiel A, Zubenko WN, Maher BS et al (2003). Sequence variations in CREB1 cosegregate with depressive disorders in women. Mol Psych 8: 611-618. 